\title{
Objective Analysis of a Two Dimensional Data Field by the Cubic Spline Technique
}

\author{
By \\ J. Michael Fritsch \\ Department of Atmospheric Science \\ Colorado State University \\ Fort Collins, Colorado
}

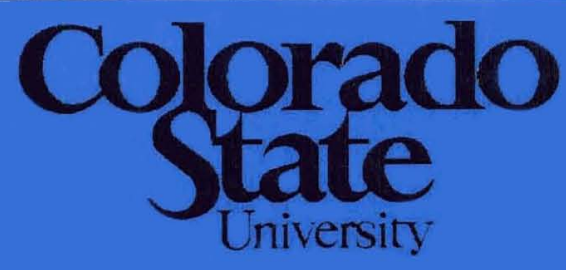

\section{Department of \\ Atmospheric Science}

Paper No. 143 
OBJECTIVE ANALYSIS OF A TWO DIMENSIONAL DATA FIELD

BY THE CUBIC SPLINE TECHNIQUE

\author{
by
}

J. Michael Fritsch

\begin{abstract}
The research described in this report was funded by the

Air Force Cambridge Research Laboratories

Contract Number F19628-68-C-0104

Project Director: Dr. D. B. Rao
\end{abstract}

Department of Atmospheric Science

Colorado State University

Fort Collins, Colorado

August, 1969

Atmospheric Science Paper No. 143 
ABSTRACT

OBJECTIVE ANALYSIS OF A TWO-DIMENSIONAL DATA FIELD

BY THE CUBIC SPLINE TECHNIQUE

A procedure to use the spline interpolation technique on an arbitrarily prescribed two-dimensional data field is described. In order to use this technique it is necessary to obtain an initial approximation to the data at the grid points. This is achieved by fitting spherical surfaces to the data. Bi-directional spline interpolation is then applied repeatedly on the grid point estimates of the data to produce convergence to the true surface.

The spline interpolation technique and another objective analysis technique developed by Gilchrist and Cressman are tested against an exact solution and the resulting analyses are compared. Real temperature, geopotential height, and wind data for various pressure surfaces are analyzed by the spline method and the results are compared to subjective analyses of the same data. 


\section{Acknowledgements}

The author wishes to express his sincere appreciation to Dr. D. B. Rao for his many hours of helpful discussion and encouragement; to $\mathrm{Dr}$. Ferdinand Baer for his constructive comnents and suggestions; to $\mathrm{Mr}$. Fred Alyea for providing the general circulation model without which a quantitative evaluation of the results would not have been possible; and to Mr. Norval McMillin for his and suggestions in programming the analysis procedure. 
Table of Contents

Page

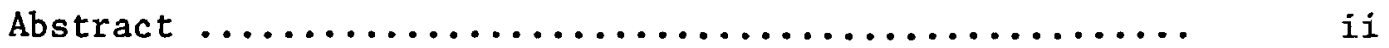

Acknowledgements $\ldots \ldots \ldots \ldots \ldots \ldots \ldots \ldots \ldots \ldots \ldots \ldots$ ii

1. Introduction $\ldots \ldots \ldots \ldots \ldots \ldots \ldots \ldots \ldots \ldots \ldots \ldots \ldots \ldots$

2. Basic Spline Theory $\ldots \ldots \ldots \ldots \ldots \ldots \ldots \ldots \ldots \ldots \ldots \ldots \ldots \ldots$

3. Mathematical Approximation to Splines ............. 8

4. Two Dimensional Considerations $\ldots \ldots \ldots \ldots \ldots \ldots \ldots \ldots \ldots$

5. Results $\ldots \ldots \ldots \ldots \ldots \ldots \ldots \ldots \ldots \ldots \ldots \ldots \ldots \ldots \ldots \ldots \ldots \ldots$

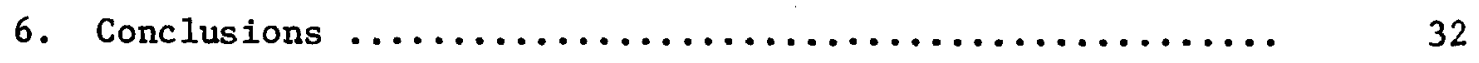

References $\ldots \ldots \ldots \ldots \ldots \ldots \ldots \ldots \ldots \ldots \ldots \ldots \ldots \ldots \ldots \ldots$ 


\section{Introduction}

With the development and continuing improvement of the electronic computer came the beginning of practical numerical weather prediction. The present day computers make it possible to use elaborate numerical models to improve forecast accuracy; however, there are certain limitations to this improvement which cannot be overcome by increasing the speed and capacity of the computer or by improving the set of equations which define the model. The two major limitations are: 1) the density of the network of observation stations; and 2) the unavoidable error, instrument or otherwise, which is introduced while making any type of measurement. The first limitation imposes a well defined limit on the scale of atmospheric motion which can be resolved by the model. of course the solution to this problem is simply to increase the density of the observing network thereby obtaining the "scale of data" necessary for predicting the corresponding scale of motion.

The second limitation is far more difficult to eliminate. Any set of observations contains certain random errors as well as some small scale fluctuations (noise). In using this data in any numerical model it is of utmost importance to eliminate these errors and the noise if the final results are to be meaningful. This has been demonstrated, for example, by the studies of Best (1956) and Berggren (1957). Since meteorological prediction is an initial value problem, it becomes imperative to begin any numerical weather prediction with the "best possible" representation of the real data.

Various attempts at solving this problem have been introduced in meteorology within the past fifteen years and shall be referred to as 
"objective analysis". An appropriate definition of objective analysis was given by Gandin (1963).

"Objective analysis includes the development and realization of methods which make it possible to use the measurement data of meteorological stations to reconstruct objectively the fields of the meteorological elements [variable], or at any rate to specify their values at the nodes [grid points] of some type of regular network." Actually, objective analysis includes three distinct functions: 1) elimination or correction of gross errors in the data field; 2) interpolation of data to obtain values on a grid; and 3) smoothing of the resulting values at the grid points.

Probably the first attempt at objective analysis of meteorological data was by Kibel in 1949. Kibel used formulas based on the method of least squares to describe the field of data by second and third order polynomials. Also in 1949, Panofsky represented a field by cubic polynomials and showed that the introduction of random observational errors into the data field resulted in only minor variations in the polynomial representation.

By 1954, the need for a better objective analysis technique to be used in conjunction with the rapidly developing field of numerical weather prediction resulted in the method developed by Gilchrist and Cressman (1954). Their method was based on fitting a second degree polynomial by the method of least squares to the data in a limited area around each grid point. Wind values were incorporated in the scheme by using the geostrophic assumption to determine $\nabla h$ (where $h$ is the deviation of height from the standard atmosphere) at a data point. 
Thus each data point supplied three pieces of information, $h, \frac{\partial h}{\partial x}$, and $\frac{\partial h}{\partial y}$ to be used in the least squares fitting. For regions of little data, this method proved to be inadequate since at least six initial pieces of information were needed to determine the second degree polynomials which defined the field. In fact, Gilchrist and Cressman found that with less than ten pieces of data the calculation was subject to significant error. In regions of sufficient data, however, they found that numerical predictions based on the objective analyses were an improvement over those based on subjective analyses.

About a year after Gilchrist and Cressman (1954) introduced their objective analysis technique, Bergthorssen and Doos (1955) developed a new approach to objective analysis. Their method differed from Gilchrist and Cressman's in that they first determined what is now called the "preliminary field". This field was computed from the weighted mean of the forecast values at the grid points and the climatological norms for that time. The data obtained from the observation stations was then used in a sequence of three corrections which were then applied to the preliminary field with different weights, depending on the distance from station to grid point. The numerical predictions based on the objective analyses technique of Bergthorssen and Doos were approximately the same as the predictions based on the subjective analyses.

Approximately five years after the development of his first objective analysis technique, Cressman (1959) introduced a modification of the Bergthorssen-Doos method. In his new method, Cressman used a preliminary field which was usually the forecast for the time of the observation data. Weighted corrections, based on the new observations, 
were then applied to the preliminary field. The corrections were defined as a function of the distance (d) from grid point to station. The weight factor (W) for each correction is given by

$$
\begin{aligned}
W & =\frac{n^{2}-d^{2}}{n^{2}+d^{2}} & & \text { for } d \leq n \\
& =0 & & \text { for } d>n
\end{aligned}
$$

where $\mathrm{n}$ is a multiple of $\mathrm{N}$, the grid interval. The correction procedure was then repeated for decreasing multiples of N. Cressman's new method of objective analysis resulted in better numerical predictions than those predictions based upon his previous method of analysis. Improvements of existing techniques have been developed, most of which are based on the inclusion of additional information such as surface data, vorticity, geostrophic approximation, etc. (see Doos and Eaton, 1957; Johnson, 1957; Sasaki, 1958; Aubert, 1959; Masuda and Arakawa, 1962; and Teweles and Snidero, 1962).

Although the above objective analyses give satisfactory results for regions of sufficiently dense observation stations, it remains to develop a reliable technique which will operate satisfactorily over regions of sparse data. An attempt to develop such a technique is presented in the following sections. 


\section{Basic Spline Theory}

The problem of passing a smooth curve through a given set of points $(\mathrm{N})$ has been solved mechanically by using a thin elastic strip to define the curve (Figure 1a). This strip is commonly called a spline. Although a polynomial of degree $\mathrm{N}-1$ could be determined which would also pass through the same set of points, the curve defined by the spline will be smoother. From the theory of elasticity it can be shown that a spline will have the minimum possible strain energy (Love, 1934; Holladay, 1957), that is

$$
\int \mathrm{K}^{2} \mathrm{ds}=\text { minimum }
$$

where $\mathrm{K}$ is the curvature and $\mathrm{ds}$ is the arc length. Since strain energy is a measure of the smoothness of a curve, the spline must define the smoothest curve for a given set of points.

If, in addition to knowing the points through which the spline passes, the slopes are prescribed at these points, the spline will define a new curve (Figure 1b) having a minimum of strain energy for the new set of constraints.

The concept of obtaining a smooth curve by passing a spline through a given set of points may be applied to the analysis of data. For this purpose, the spline curve between any two data points will have to be approximated mathematically by a polynomial representation. These piecewise polynomials will then have to be joined together under certain specified constraints like the continuity of the function and its derivatives at the data points. These constraints, of course, depend on the nature of the phenomenon under investigation. Fowler and Wilson (1966) have developed a method of determining a series of cubic equations which, when spliced together with continuous slope and curvature 


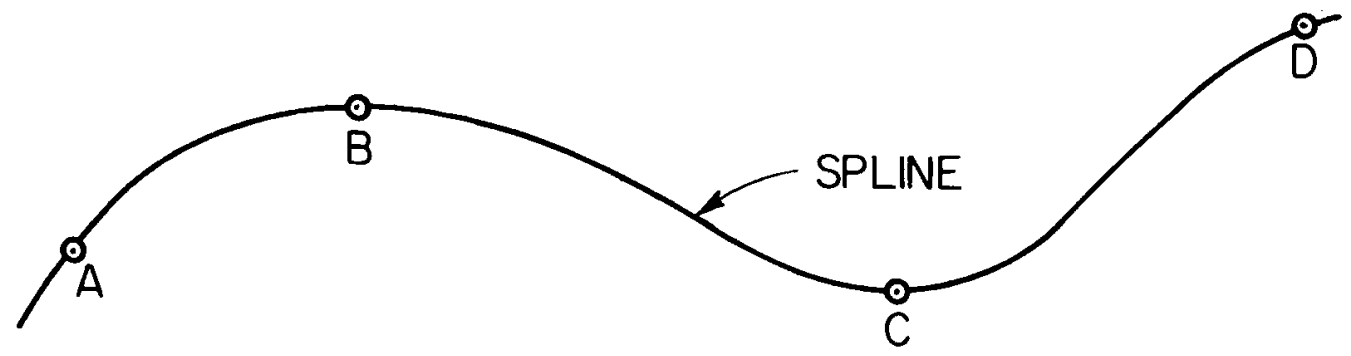

Fig. la: Spline passing through points A, B, C, and D.

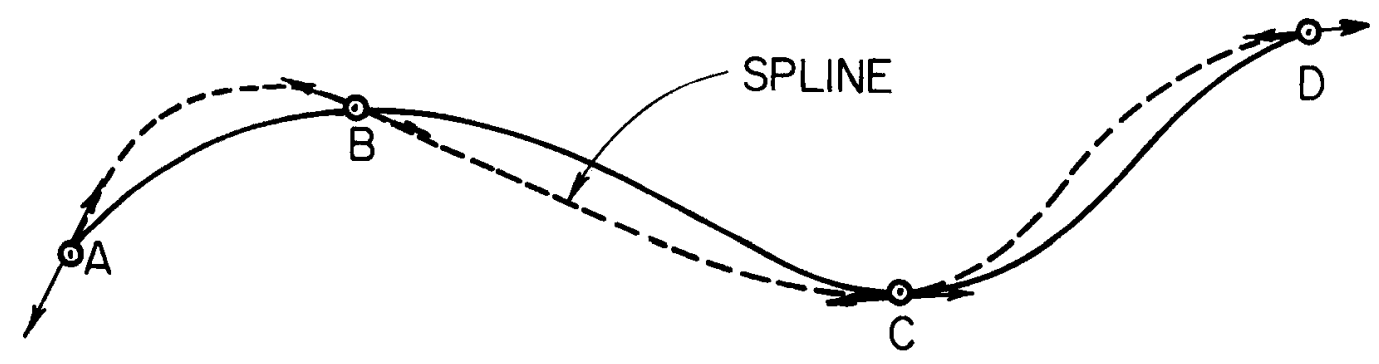

Fig. 1b: Spline passing through points A, B, C, and D where slopes have been prescribed at the points.

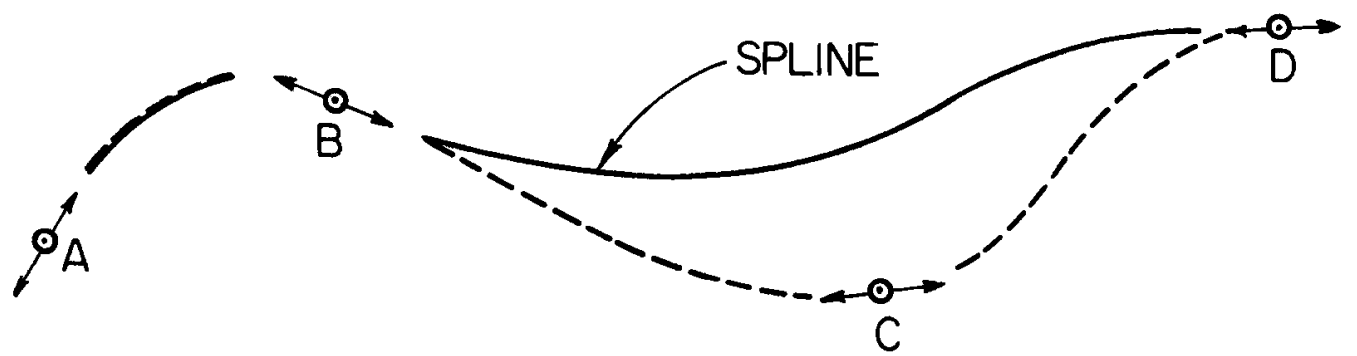

Fig. 1c: Spline curve which results when one of the constraints (point C) has been removed. 
at the junction points, approximate a spline for a given set of data and slopes. Pearce (1968) used piecewise quadratic polynomials to allow for the sharp but real changes which occur in representing a vertical wind profile.

Normally it is not desirable to fit a curve exactly through all the data points, and so, some type of smoothing is performed on the data. It is interesting to note now, that if one of the constraints in Figure $1 b$ is removed, the resulting position of the spline (Figure $1 c$ ) is one of even less strain energy. That is, the spline defines a smoother curve. Thus an equation which approximates the new spline should give a smoother representation of the data. However, since it is not desirable to completely eliminate any data points, the new spline could instead be used to determine the magnitude and direction of the movement of a data point such that "controlled" smoothing may be done. Fowler and Wilson (ibid.) made use of this idea to smooth their series of continuous cubic equations. 


\section{Mathematical Approximation to Splines}

The mathematical development of the more widely used spline approximation, the cubic spline, is described below. A cubic spline fitting requires a general third degree polynomial between any two points of a given set of data. Hence, ten initial conditions must be known. If the coordinate system is translated and rotated so that the first point is at the origin and the second is on the $x^{\prime}$-axis, the general equation for a third degree polynomial reduces to

$$
\mathrm{y}^{\prime}=\mathrm{Ax} \mathrm{x}^{3}+\mathrm{Bx^{ \prime 2 }}+\mathrm{Cx}+\mathrm{D}
$$

where the primes indicate the new coordinate axes. The solution to this new system requires only four initial conditions. Assuming that the coordinates of the two points (endpoints) are known, it remains to determine two additional conditions. These are obtained in the following manner. Consider Figure 2. A circle is fitted to the set of points defined by the endpoint $B$, and the two adjacent points, $A$ and $C$. The derivative of the resulting equation may then be solved for the slope at B. Similarly, the slope at $\mathrm{E}$ is determined using points $\mathrm{D}, \mathrm{E}$ and $\mathrm{F}$. The four initial conditions are then:

$$
\begin{array}{ll}
\text { at the first endpoint } & \begin{array}{l}
x^{\prime}=y^{\prime}=0 \\
\text { slope }=s 1^{\prime}
\end{array} \\
\text { at the second endpoint } & x^{\prime}=d, y^{\prime}=0 \\
\text { slope }=S 2^{\prime}
\end{array}
$$

where $\mathrm{d}$ is the distance between the endpoints.

The equation for the slope is given by the first derivative of (1).

$$
\frac{d y^{\prime}}{d x^{\prime}}=3 A x^{\prime}+2 B x^{\prime}+C
$$




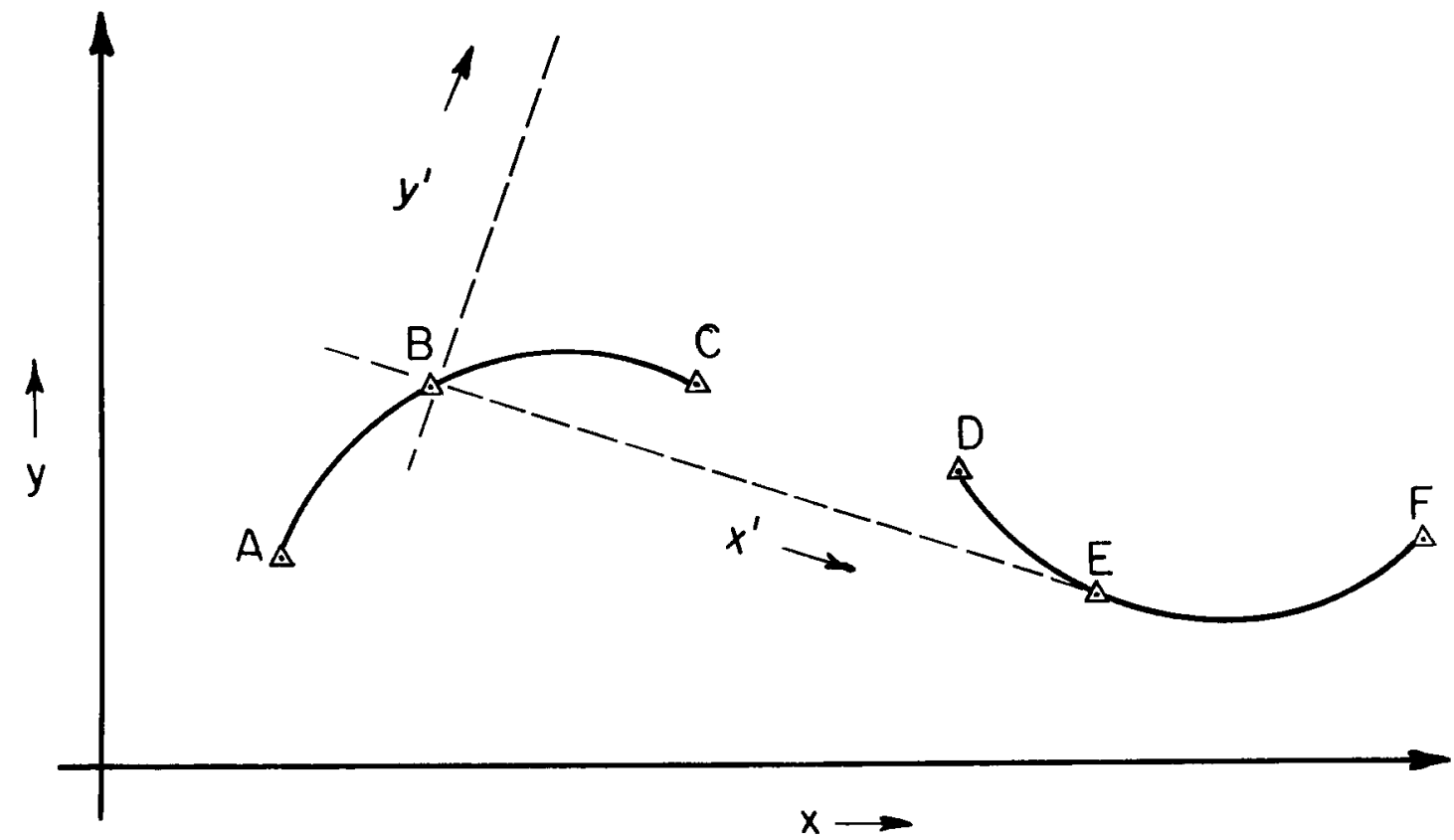

Fig. 2: Determination of slopes at data points by fitting circles to the data.

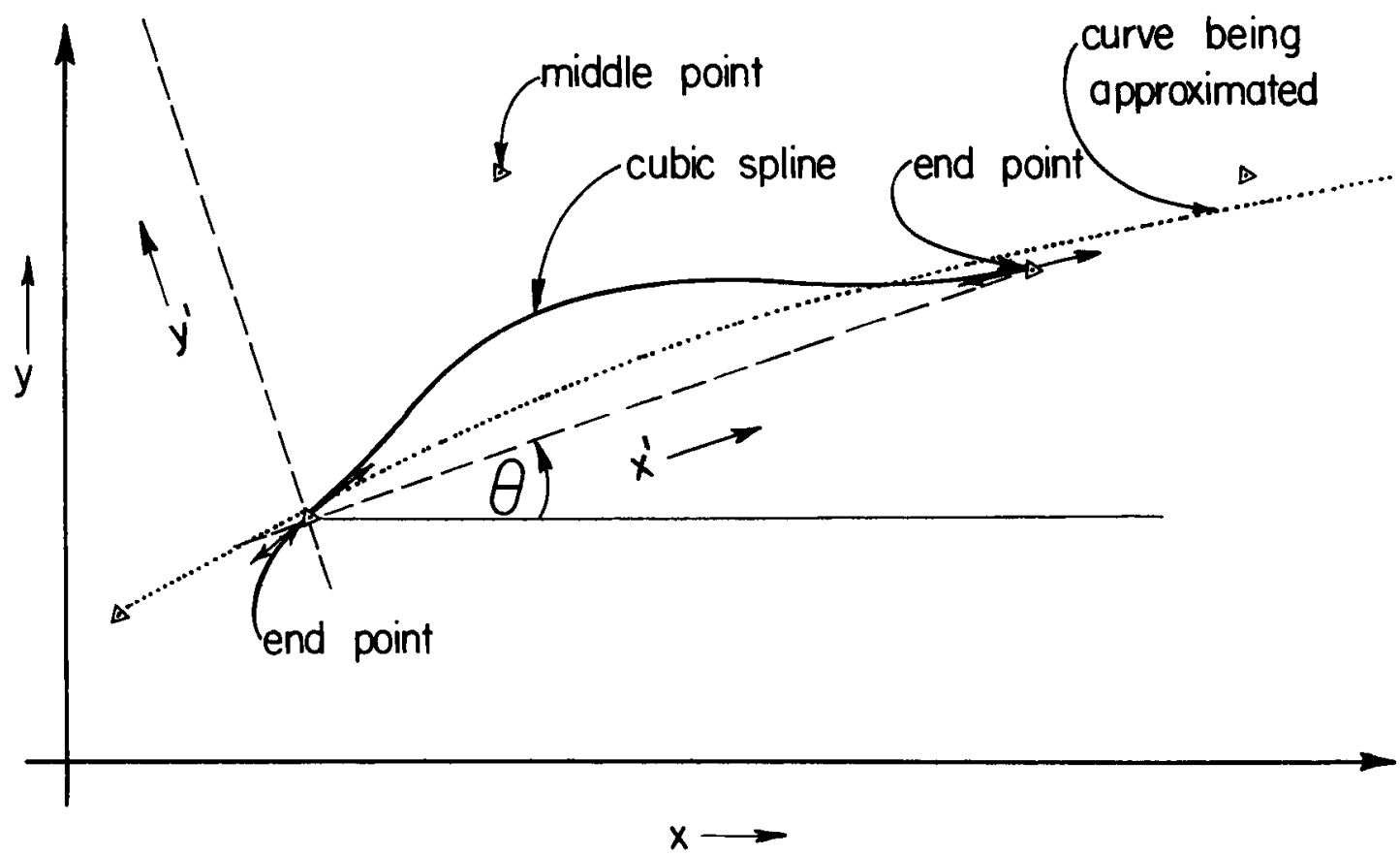

Fig. 3: Normal position assumed by the cubic spline when fitted to the endpoints of a three data interval. 
The system consisting of equations (1) through (6) may now be solved in terms of $\mathrm{SI}^{\prime}, \mathrm{S} 2^{\prime}$ and $\mathrm{d}$. The resulting expression for $\mathrm{y}^{\prime}$, then, is

$$
y^{\prime}=\frac{\left(S 1^{\prime}+S 2^{\prime}\right)}{d^{2}} x^{\prime 3}-\frac{\left(2 S 1^{\prime}+S 2^{\prime}\right)}{d} x^{\prime 2}+S 1^{\prime} x^{\prime}
$$

Due to the rotation of the coordinate system, the endpoint slopes in the original system, $\mathrm{S} 1$ and $\mathrm{S} 2$, have been transformed to new values, $\mathrm{S} 1$ ' and S2', in the primed system. This transformation is given by:

$$
\begin{aligned}
& \mathrm{S} 1^{\prime}=\frac{\mathrm{S} 1-\mathrm{TR}}{1+\mathrm{S} 1 \cdot \mathrm{TR}} \\
& \mathrm{S} 2^{\prime}=\frac{\mathrm{S} 2-\mathrm{TR}}{1+\mathrm{S} 2 \cdot \mathrm{TR}}
\end{aligned}
$$

where $T R$ is the tangent of the angle of rotation $(\theta)$.

Now consider a data interval to be the interval defined by the endpoints of three successive data points. A cubic equation fitted to the endpoints of each successive interval for a given set of data will usually pass between the curve to be approximated and the middle data point of the interval (see Figure 3). This suggests an iterative smoothing procedure which will result in the convergence of the data towards the curve.

Starting with the first interval, a cubic is constructed for that interval. The middle data point is then adjusted towards the cubic. Since the location of the curve to be approximated is not known in most cases, the middle point is only moved some fraction of the total distance between the point and the cubic curve. The procedure is repeated in the succeeding intervals. Figure 4 a demonstrates this procedure where the adjusted points are indicated by the higher subscripts. For 


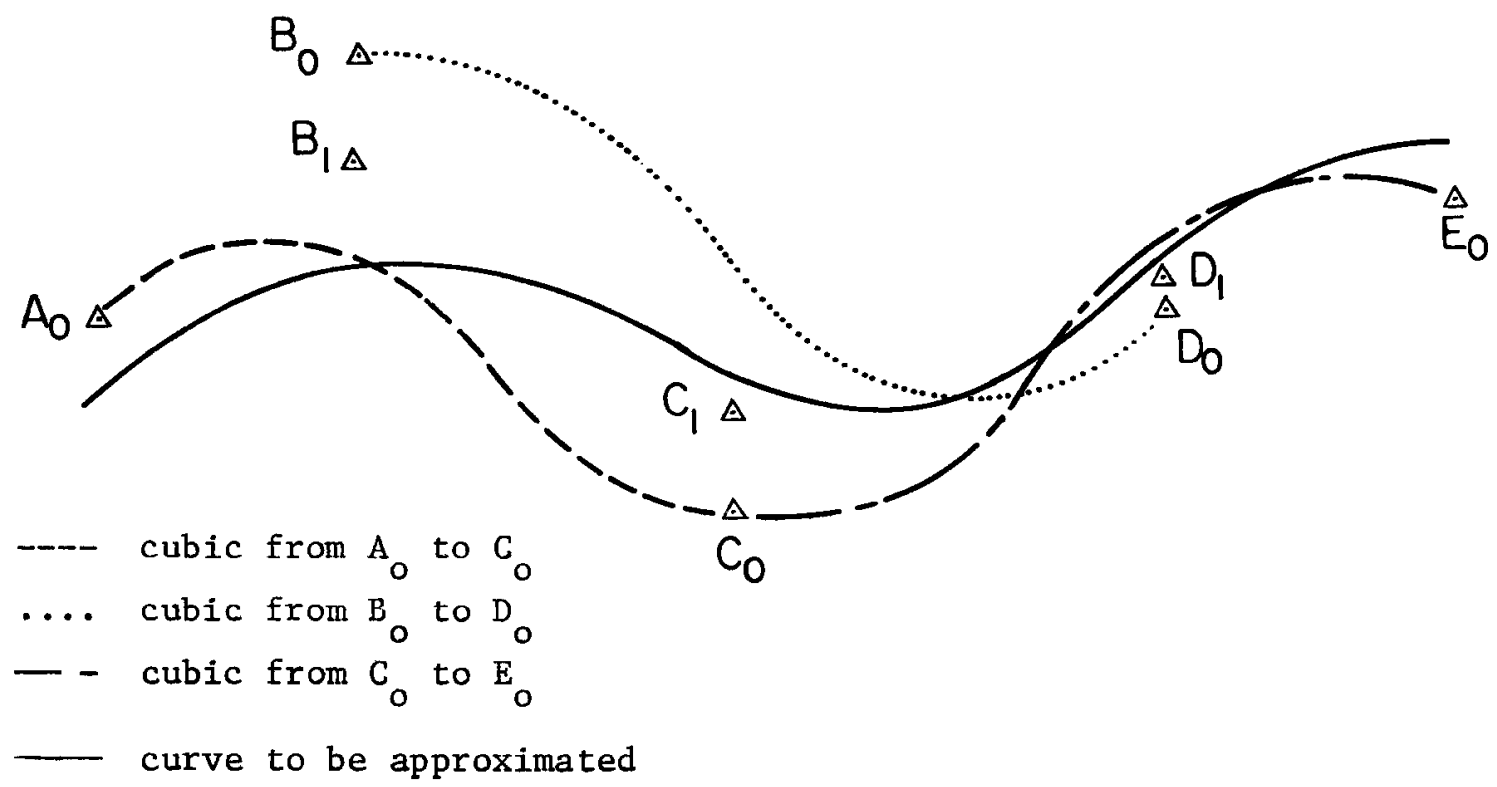

Fig. 4a: Set of three cubic splines approximating a curve.

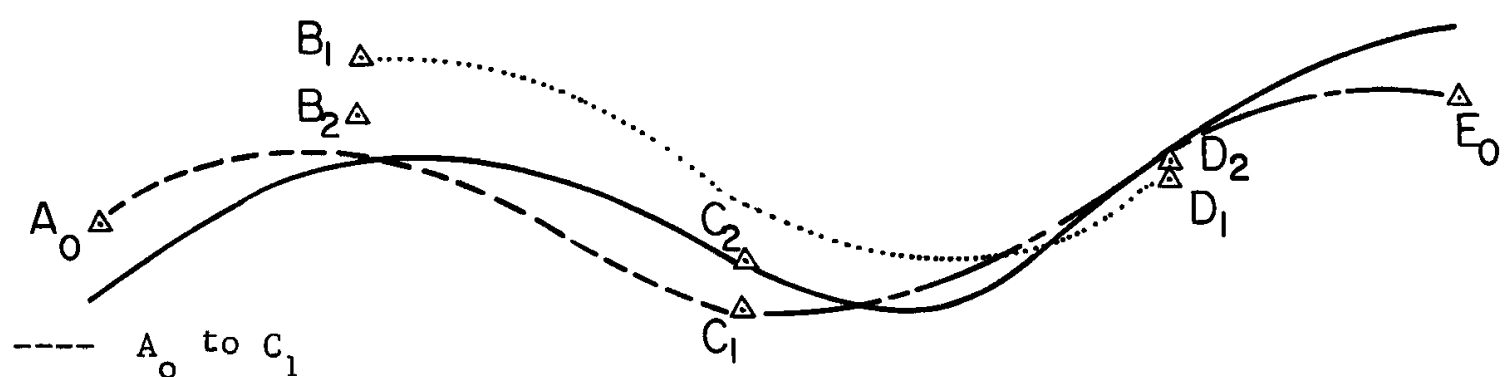

$\ldots B_{1}$ to $D_{1} \quad$ _... curve to be approximated

- $\mathrm{C}_{1}$ to $\mathrm{E}_{\mathrm{o}}$

Fig. 4b: Second iteration in the cubic spline convergence.

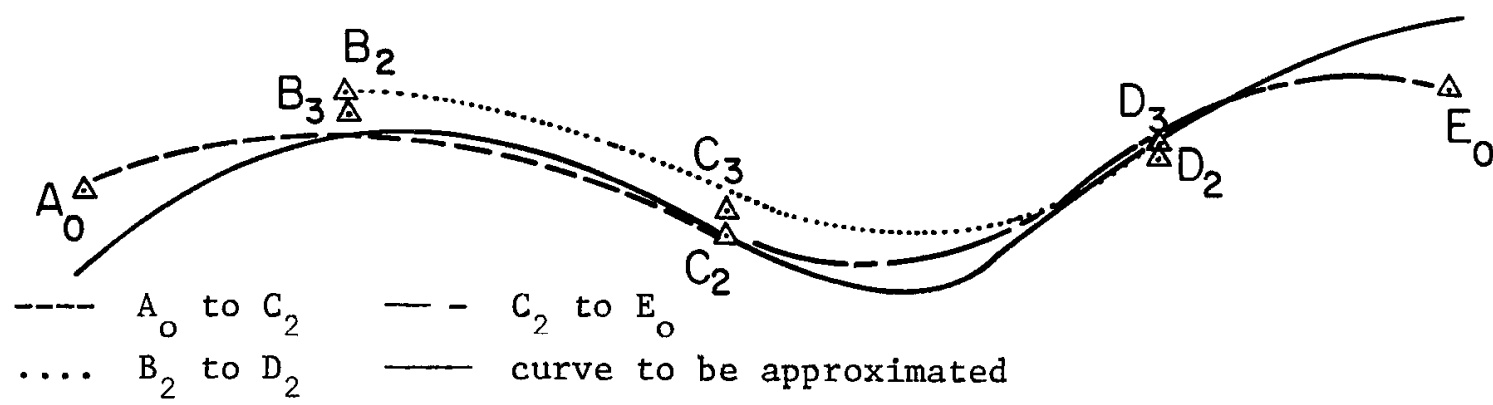

Fig. 4c: Third iteration in the cubic spline convergence. 
example, a cubic is fitted to $A_{0}$ and $C_{0}$. The middle point, $B_{0}$, is then moved toward the cubic to its adjusted position, $B_{1}$. In the next interval, the cubic is fitted to $B_{0}$ and $D_{0}$ which adjusts $C_{0}$ to $C_{1}$. Similarly $D_{0}$ is adjusted to $D_{1}$ in the interval $\left(C_{0}, E_{0}\right)$. Upon completion of the data adjustment for all intervals, the entire process is repeated until satisfactory convergence is achieved or the benefit of additional smoothings becomes impractical. Figures $4 \mathrm{~b}$ and $4 \mathrm{c}$ depict the second and third iterations in a series of three smoothing iterations for a set of five data points. In general, spline interpolation converges rapidly as shown by Ahlberg and Nilson (1963), and has the additional property of being insensitive to round-off errors. 


\section{Two-Dimensional Considerations}

The results of approximating curves by splines have been so successful (Curtis and Powel1, 1966; Wa1sh, Ahlberg and Nilson, 1962) that it would seem desirable to extend the theory to approximate surfaces. Birkhoff (1966) developed a method using bicubic spline interpolation which approximates surfaces on a rectangular field given the data value (u) at all grid points, the normal derivative $(\partial u / \partial n)$ at the boundary grid points of each elemental rectangle, and the cross derivatives $\left(\partial^{2} \mathrm{u} / \partial \mathrm{x} \partial \mathrm{y}\right)$ at the four corners of the field. In practice, however, most data fields are not known at a regular grid network and the problem is therefore to interpolate the known data to the grid points and smooth the resulting fields.

Since circles were used successfully by Fowler and Wilson (ibid.) to obtain an approximation to the slope at each point in their curve fitting routine, it would seem logical to fit spheres to the data to approximate the surface and slope in a surface fitting routine. Since the value of the surface is desired only at the grid points, the problem may be reduced to one of splicing the surfaces of the spheres together at a discrete number of points.

Given an arbitrarily located set of two dimensional data points, the points are ordered according to increasing values of the $x-$ coordinate. A grid network is defined (grid length is arbitrary) to cover the data field such that all data points fall within the network. Since for a given grid point, not all the data influence the value at that point, what shall be referred to as the "band of influence" is defined for each grid line $(y=$ constant). The vertical plane which is coincident with the grid line is called the grid plane. 
For a given grid line then, those data points which fall into the band of influence are used to define the spheres. The surface value at each grid point on the grid line can then be determined by substituting the coordinate of the grid point into the equation for the appropriate sphere. The equation for a sphere is given by:

$$
(x-a)^{2}+(y-b)^{2}+(z-c)^{2}=x^{2}
$$

Given four data points, (8) may be solved for a, b, and $c$, the coordinates of the center of the sphere, and $r$, the radius of the sphere. For a given grid line, $y=y_{j}$, which passes through the sphere, and grid point, $x=x_{i}$, in the domain of the sphere, (8) may be solved for the surface, $z_{i j}$, at the grid point.

In order to define the surface from the beginning of the grid to the first data point, the first three data points in the band of influence are used to quadratically extrapolate backwards past the beginning of the grid. Based on this extrapolation, three dummy data points are created. The requirement on the location of these dummy points is that the first two are located outside the grid boundary and the third located between the boundary and the first real data point. The reason for this will be explained below. Three dummy points are also determined at the other end of the grid to generate data from the last real data point to the end of the grid.

The surface value at the first grid point along a grid line is determined by fitting a sphere to the first four data points and substituting the grid point into the equation for the sphere. The first grid point is always made to fall between the second and third data points. If the succeeding grid point also falls between the second and 
third data points, its surface value is obtained using the same sphere. As soon as the succeeding grid point falls past the third data point, a new sphere is used to obtain the surface value for the new grid point. The new sphere is determined from the last three data points of the previous sphere and the next data point in succession (see Figure 5). Thus, surface values at all grid points represent the "midsection", so to speak, of the data which defines each sphere.

This procedure is repeated for each grid line until an approximation to the surface has been determined at all grid points.

The resulting data values at the grid points are checked for error by comparing the grid point value to the mean of the data values in the band of influence being considered. If the difference between a grid point value and the mean data value is greater than two standard deviations of the real data, the grid point value is replaced by a linear interpolation between the two nearest acceptable grid values along the grid line (one acceptable grid value is taken from each side of the rejected grid value). If the first grid point is rejected, it is replaced by the mean of the data in the band of influence. This procedure is to some extent arbitrary, since the mean of the entire data field may be used instead of the mean for the band of influence. Also, in some analyses it may be desirable to restrict the magnitude of the extreme values, thus, the number of standard deviations of the real data is left as a variable input parameter. Since it is possible for two successive grid point values to occur at opposite extremes within the prescribed number of standard deviations of real data, the difference between two successive grid values may be as large as twice the number of standard deviations which was prescribed. Such a change may or may not be 


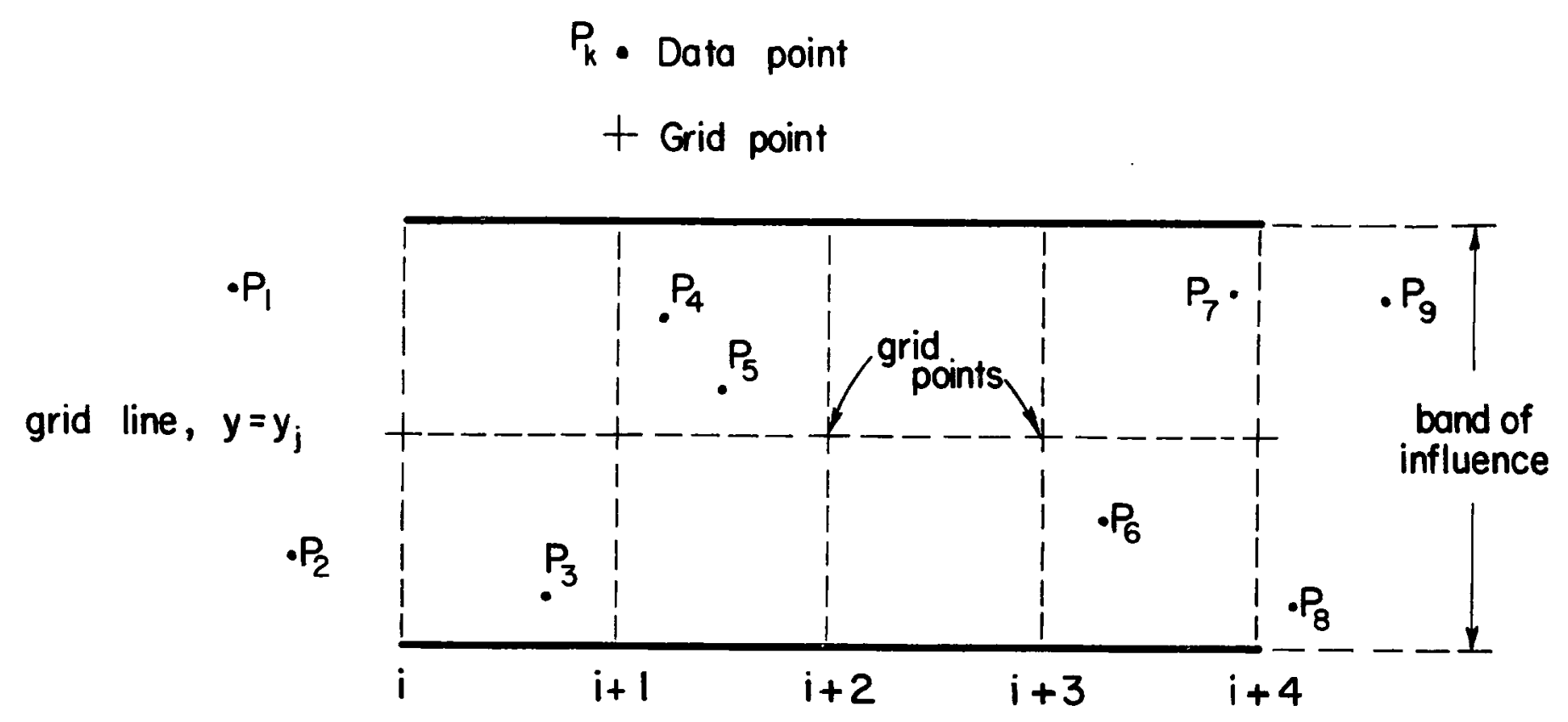

\begin{tabular}{cl}
\multicolumn{2}{c}{ Uor } \\
Grid Point & Data Points \\
$i, j$ & $P_{1}, P_{2}, P_{3}, P_{4}$ \\
$i+1, j$ & $P_{2}, P_{3}, P_{4}, P_{5}$ \\
$i+2, j$ & $P_{4}, P_{5}, P_{6}, P_{7}$ \\
$i+3, j$ & $P_{4}, P_{5}, P_{6}, P_{7}$ \\
$i+4, j$ & $P_{6}, P_{7}, P_{8}, P_{9}$
\end{tabular}

Fig. 5: Selection of data points for determination of surface values at the grid points using spheres. 
realistic, so all grid point values (except those at $x=x_{1}$ ) are subjected to an additional error check which is based upon the maximum permissible slope (MPS) between grid points. The MPS is a function of the variable being analyzed and is therefore an input parameter. Beginning with the second grid point, $x_{2}$, the points, $x_{i}$, along the boundary, $y_{1}$, of the grid are compared to the grid values at the last acceptable grid point, $\left(x_{i}, y_{2}\right)$, and $\left(x_{i}, y_{3}\right)$. If the slope from the point $\left(\mathrm{x}_{i}, \mathrm{y}_{1}\right)$ to any two of the neighboring points is greater than MPS the grid point value at $\left(x_{i}, y_{1}\right)$ is replaced in the same manner as described above. For the points $\left(x_{i}, y_{j} ; i \geq 2,1<j<j_{\max }\right)$ each grid value along the grid lines, $y_{j}$, is compared to the two neighboring grid values $\left(x_{i-1}, y_{j}\right)$ and $\left(x_{i}, y_{j-1}\right)$. If the slope from the point $\left(x_{i}, y_{j}\right)$ to either of the neighboring points is greater than MPS, the grid point value is replaced as described above. The error check at the boundary, $y_{j_{\max }}$, is analogous to the error check at the boundary, $y_{1}$. Errors occurring near the end of a grid line may not have an acceptable adjacent grid value in the positive $x$-direction. In this situation a second order Taylor's extrapolation is used from the last three acceptable grid values to the end of the grid.

Starting with the first grid line, $y_{1}$, each grid line is smoothed using the cubic spline routine as outlined in Section 3 . Upon completion of smoothing in the $x$-direction, the entire field is smoothed in the same manner in the $y$-direction. Repeated smoothings in the $x$ and $y$ directions eliminate directional bias, and after three or four of these bi-directional smoothings, the grid point values converge to a surface. 


\section{Resu1ts}

In order to properly test the spline method it would be advantageous to know an exact solution for the surface. Thus, in addition to a qualitative evaluation of the results, a quantitative measure of the error could be determined. This would have the additional advantage of being able to compare, quantitatively, the error of the spline objective analysis to the error of other methods.

Based on these considerations, a test was constructed using a solution for the stream function for the upper level of a two layer baroclinic spectral general circulation model. The solution was for the northern hemisphere and could be interpreted as the height of the $250 \mathrm{mb}$ pressure surface. A total of 356 data points were selected, most of which are established radiosonde stations (see Figure 6). An $18 \times 72$ grid (grid length $=5^{\circ}$ latitude) was used and the height at all grid points was determined from the exact solution. The exact solution is shown in Figure 7 .

The results of applying the spline technique to the data at the radiosonde locations are shown in Figure 8 . Another objective analysis technique (Cressman, 1959) was applied to the same data and the results are shown in Figure 9. The standard error was computed for both techniques with the result that the error for Cressman's technique was on the order of twice the error of the spline technique. The percent error for the spline solution was calculated at each grid point and is shown in Figure 6 . The only region where greater than $10 \%$ error occurs is located over that section of the Pacific ocean where there is an extreme lack of data (see Figure 6). The mean error for the entire northern 


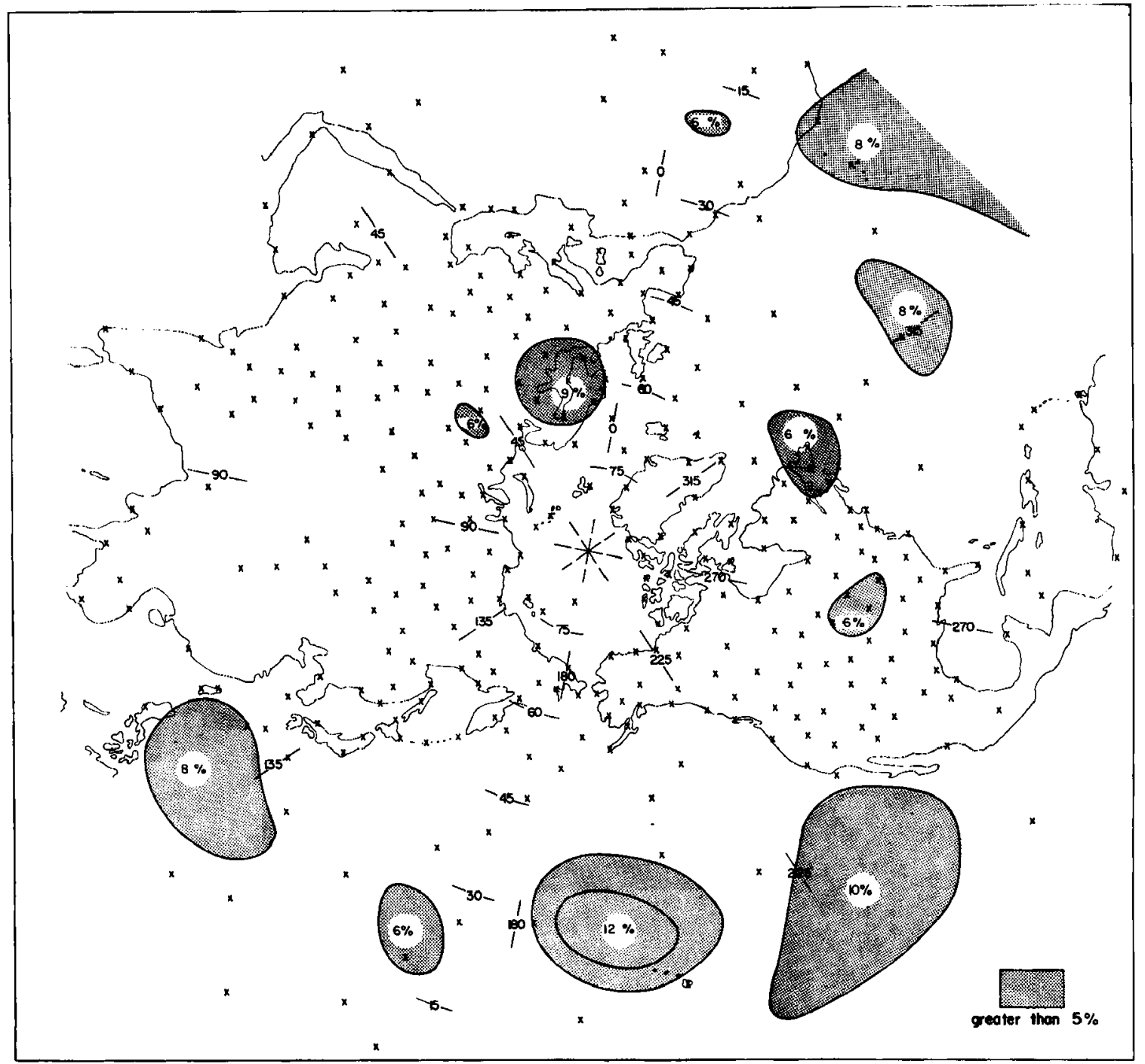

Fig. 6: Data point locations (marked by $X$ ) and percent error for the spline approximation to the exact solution. Areas not shaded are less than $5 \%$ error. 


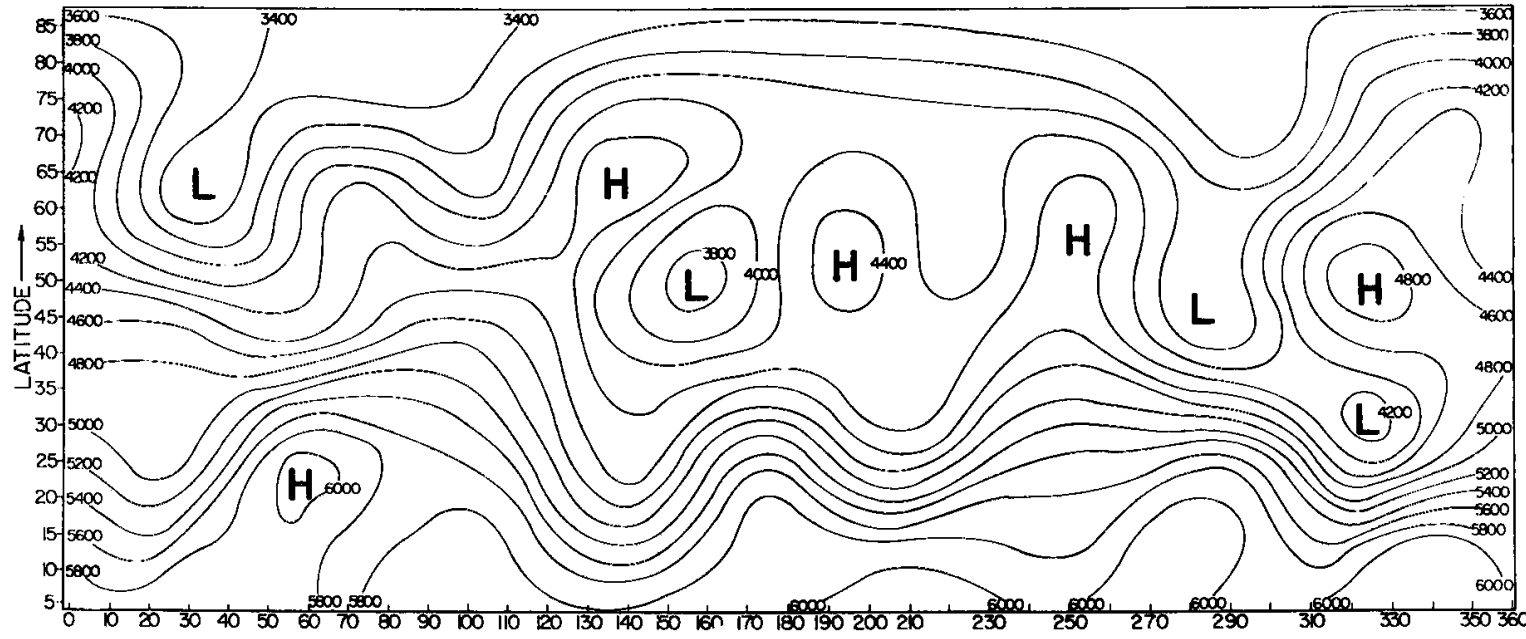

Fig. 7: Exact solution for the stream function for the upper level of a two layer baroclinic spectral general circulation model.

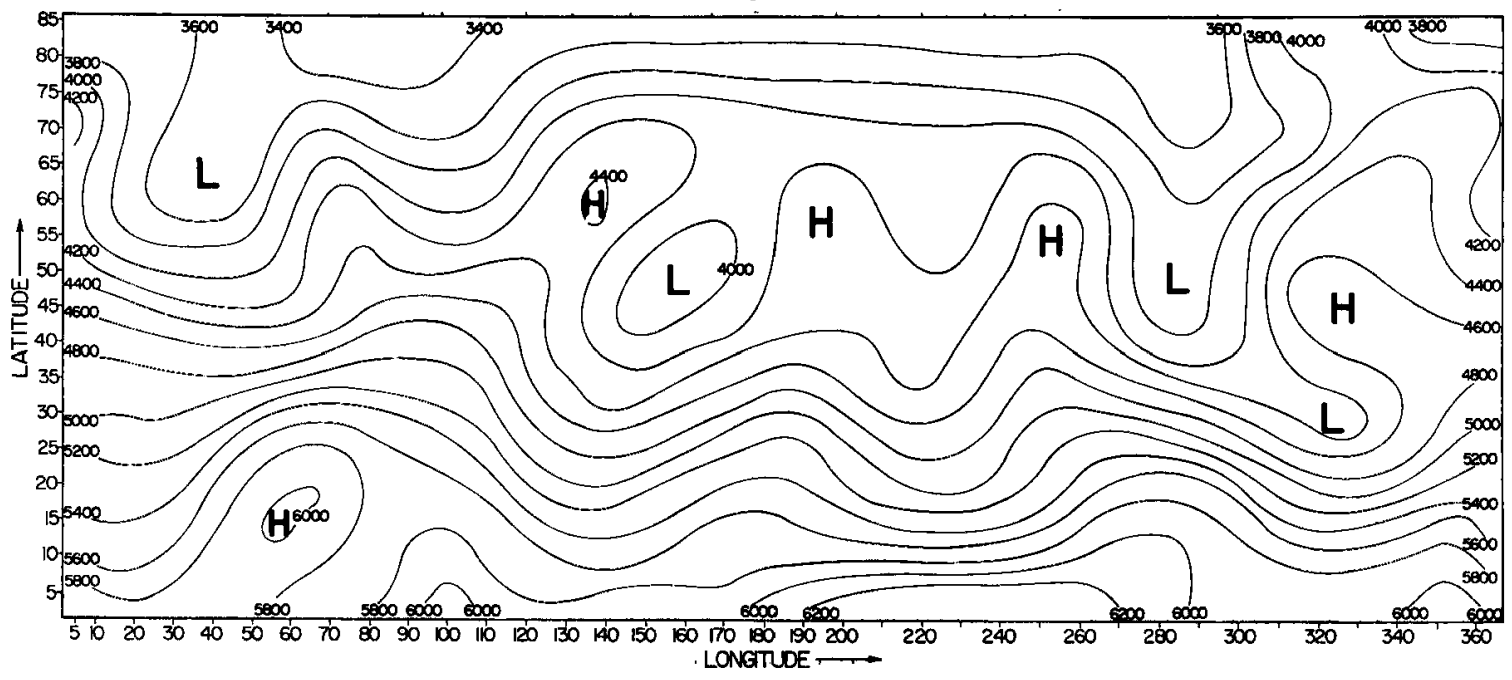

Fig. 8: Spline approximation to the exact solution. Standard error $=147$.

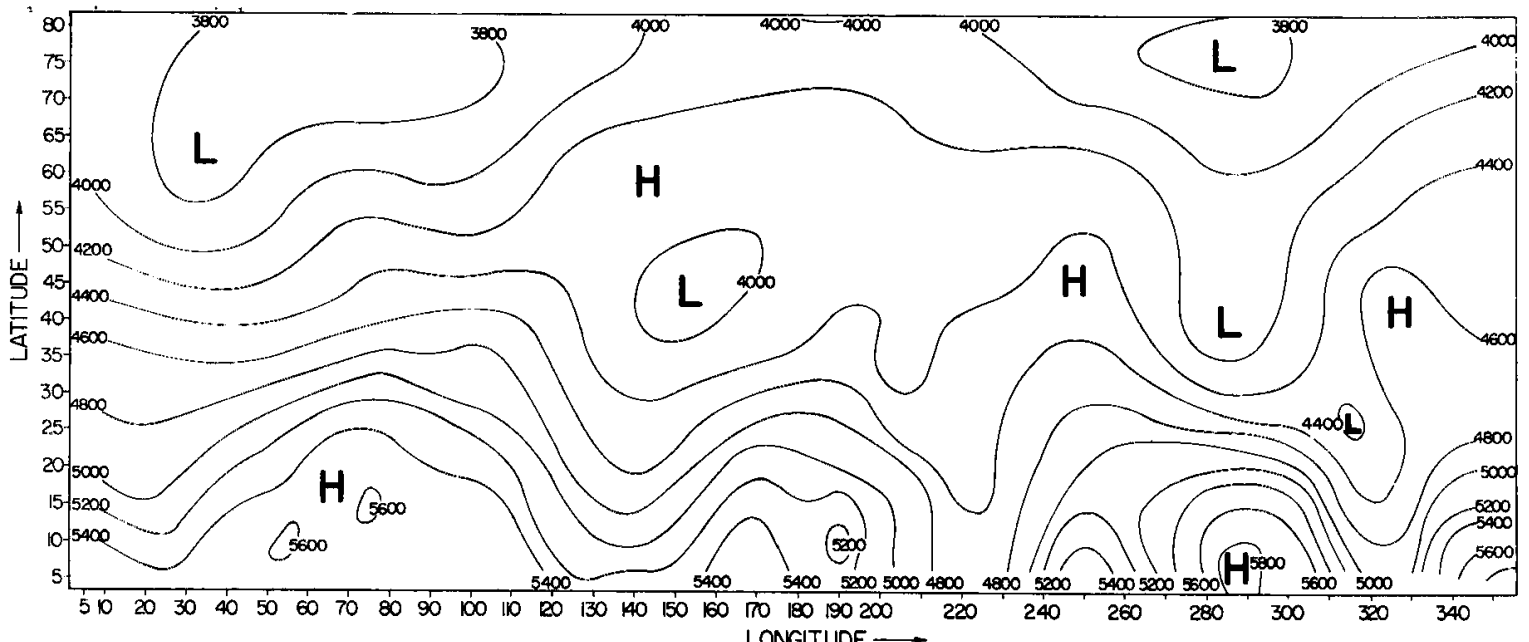

Fig. 9: . Cressman's approximation to the exact solution. Standard error $=321$. 
hemisphere was approximately $3 \%$ and in regions of good data coverage this figure usually dropped to 0 to $2 \%$.

In practical weather analysis, quite frequently it becomes necessary to analyze pressure gradient and/or temperature discontinuities (fronts). Since one of the functions of most objective analyses is to smooth the data, often the discontinuity is lost completely or is smoothed to such an extent that its frontal characteristics are no longer significant. Since it is usually desirable to maintain frontal characteristics, a test was constructed to determine how the cubic spline technique performs on discontinuities. The temperature data for the United States on December 28, 1966 was selected for analysis. On this date a particularly sharp cold front was located in the mid-section of the country. Figures 9, 11, and 13, which are the spline analyses of the front at various pressure surfaces, indicate that the loss of frontal characteristics appears to be minimal, even at the $850 \mathrm{mb}$ level where the front is most intense. Figures 10,12 , and 14 are the corresponding subjective analyses. A comparison of objective and subjective analyses shows good agreement both along and across the front. It is possible that the frontal characteristics may be even better resolved if a quadratic spline is used as, for example, by Pearce.

For the same time and location as the temperature data, the wind and height data were also analyzed objectively (Figures 15, 17, 19, 21, 23, and 25) and subjectively (Figures 16, 18, 20, 22, 24, and 26). Examination of these and the previous results indicates that unless a particular feature of a data field (for example, a steep gradient, a maximum, or a minimum) is "supported" by more than one or two pieces of data, the feature is smoothed rather markedly. More explicitly, the 
wind maximum located at $x=17, y=16$ on Figure 16 is defined by only one piece of data. On the corresponding spline analysis, Figure 15, this maximum is not well defined. Likewise, the wind minimum at $x=45$, $y=12$ on Figure 20 does not show up well on the corresponding spline analysis, Figure 19. Based upon one piece of data, the $500 \mathrm{mb}$ temperature minimum is split into two sections in Figure 12, whereas the spline analysis of the same data produces only one minimum region. Of course, in most situations there are more than one or two pieces of data to define the significant features and so there is generally good agreement between the subjective analyses and the spline analyses. 


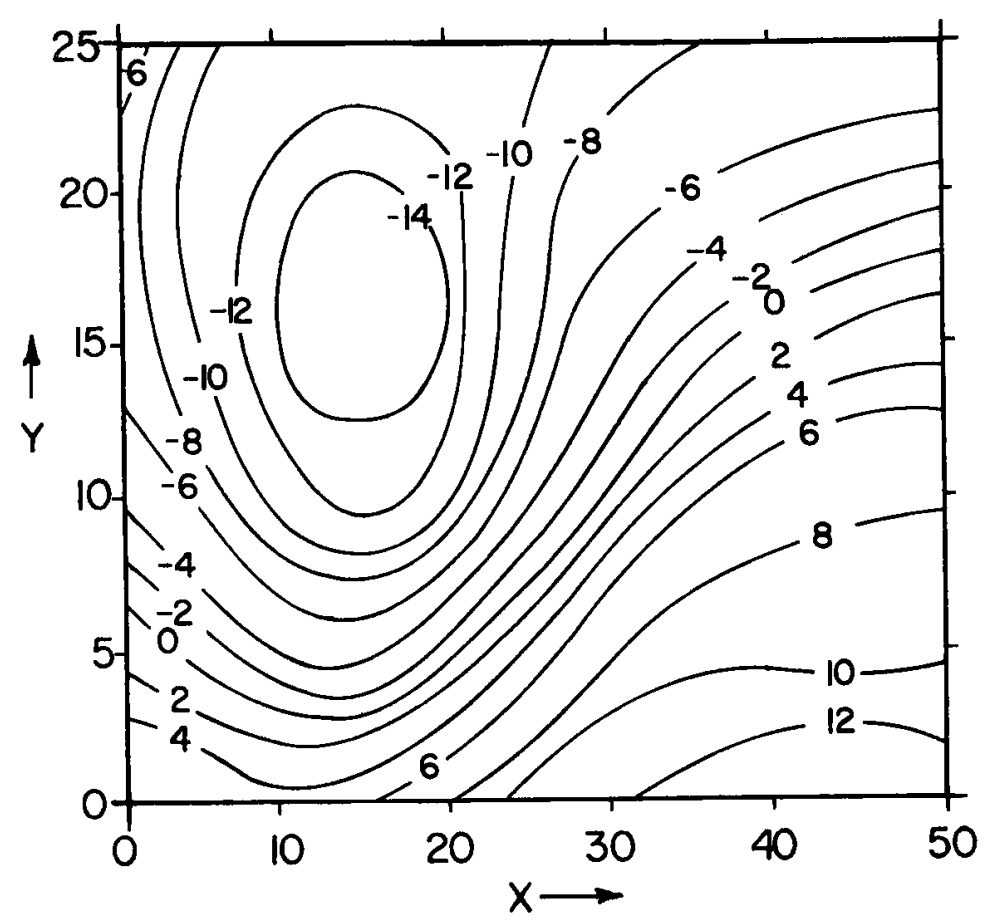

H'ig. 9: Spline analysis of the $850 \mathrm{mb}$ temperatures for central United States, 00 GMT, December 28, 1966.

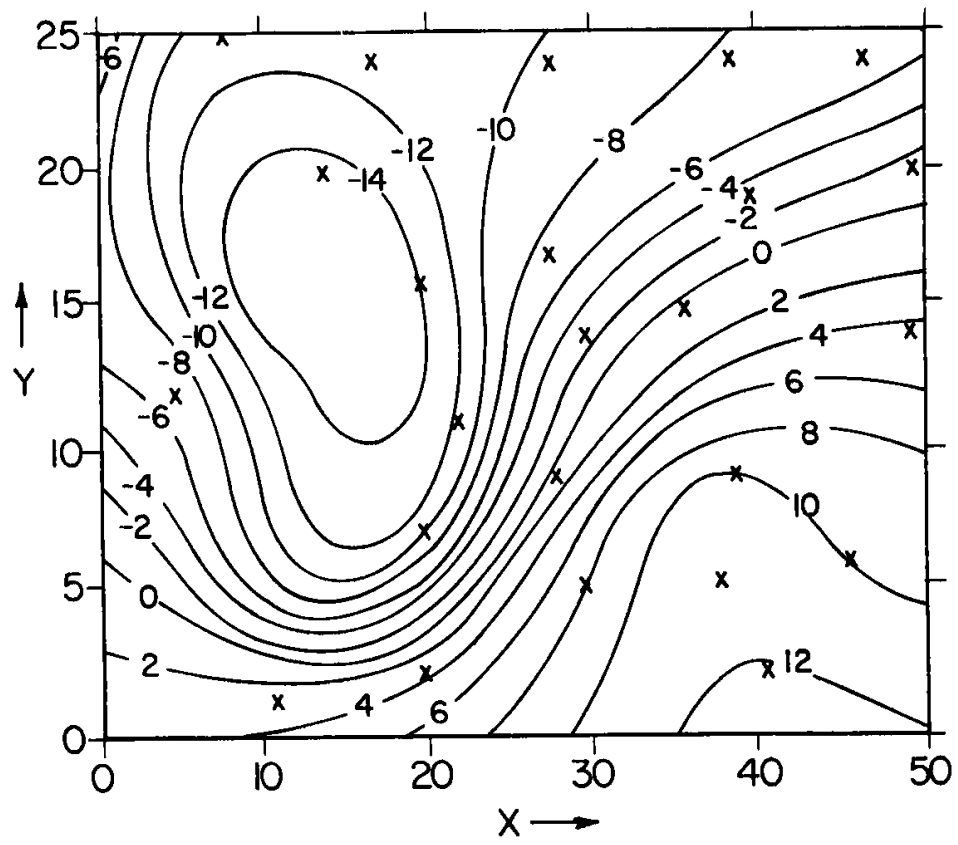

Fig. 10: Subjective analysis of the $850 \mathrm{mb}$ temperatures for central United States, 00 GMT, December 28, 1966. Radiosonde locations are indicated by $\mathrm{X}$. 


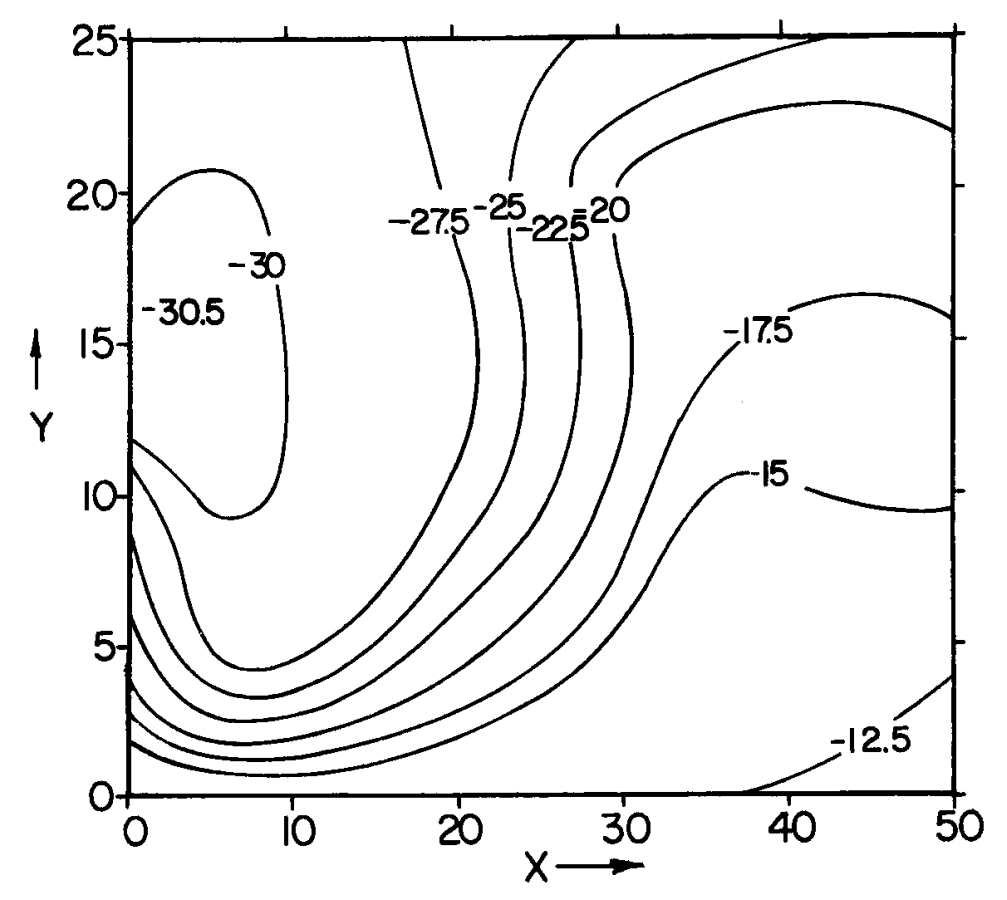

Fig. 11: Spline analysis of the $500 \mathrm{mb}$ temperatures for central United States, 00 GMT, December 28, 1966.

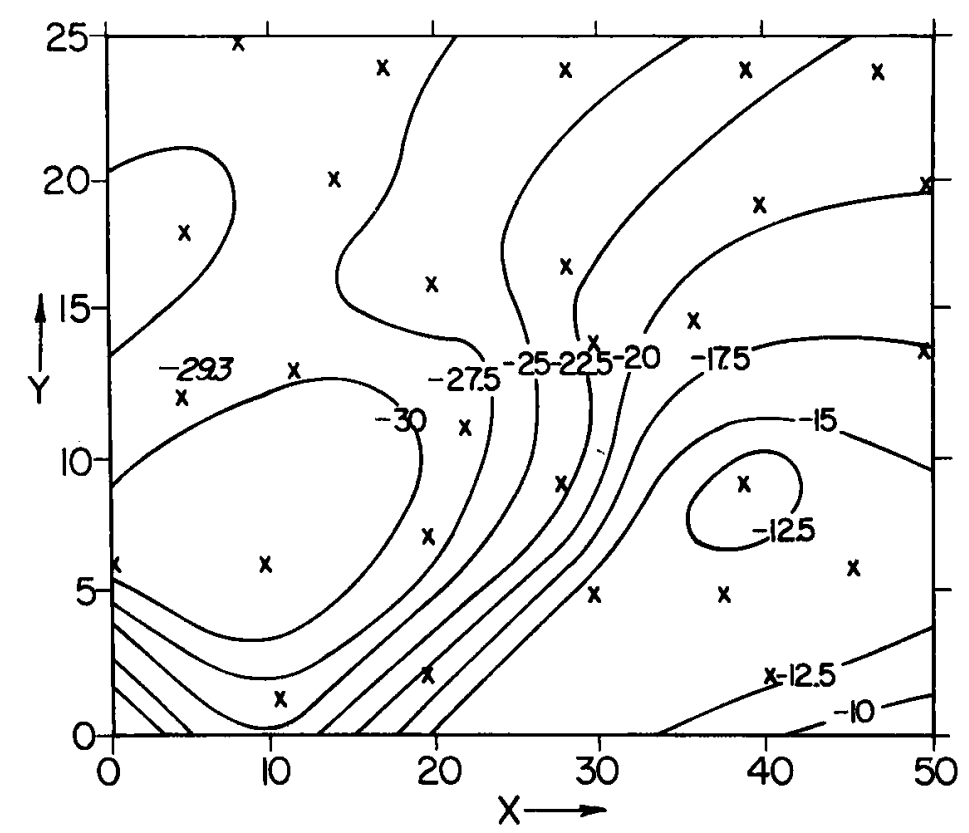

Fig. 12: Subjective analysis of the $500 \mathrm{mb}$ temperatures for central United States, 00 GMT, December 28, 1966. Radiosonde locations are indicated by $\mathrm{x}$. 


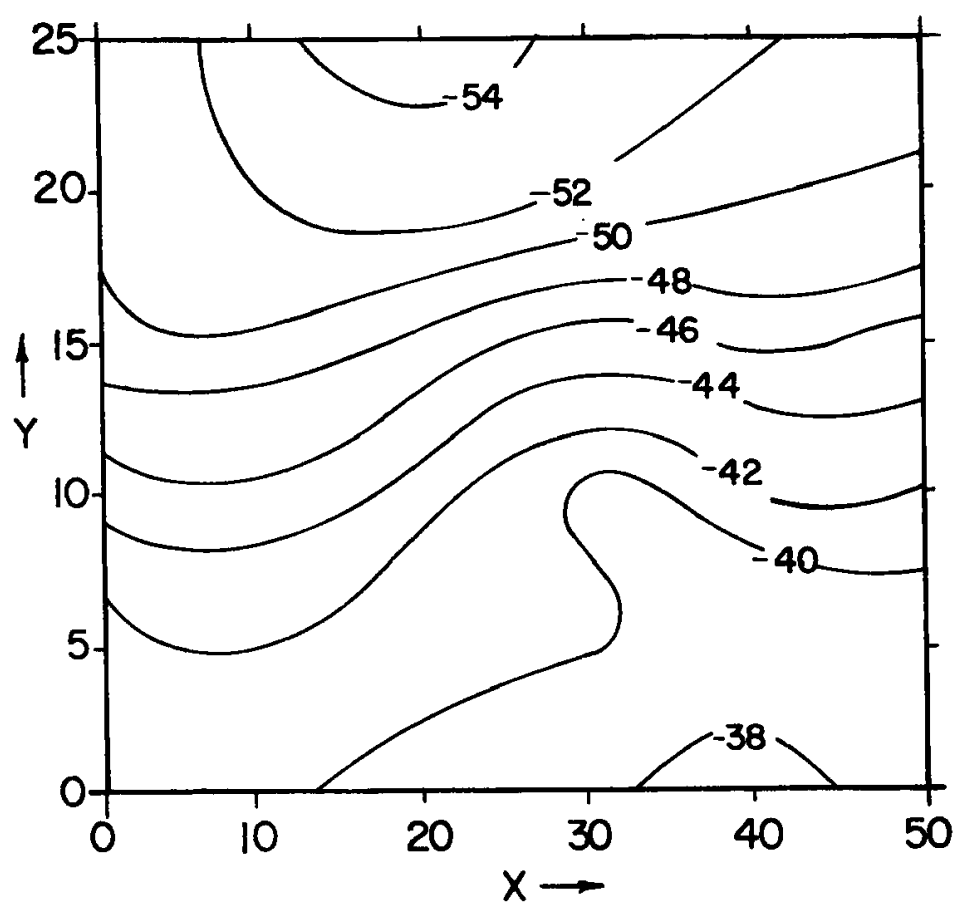

Fig. 13: Spline analysis of the $300 \mathrm{mb}$ temperatures for central United States, 00 GMT, December 28, 1966.

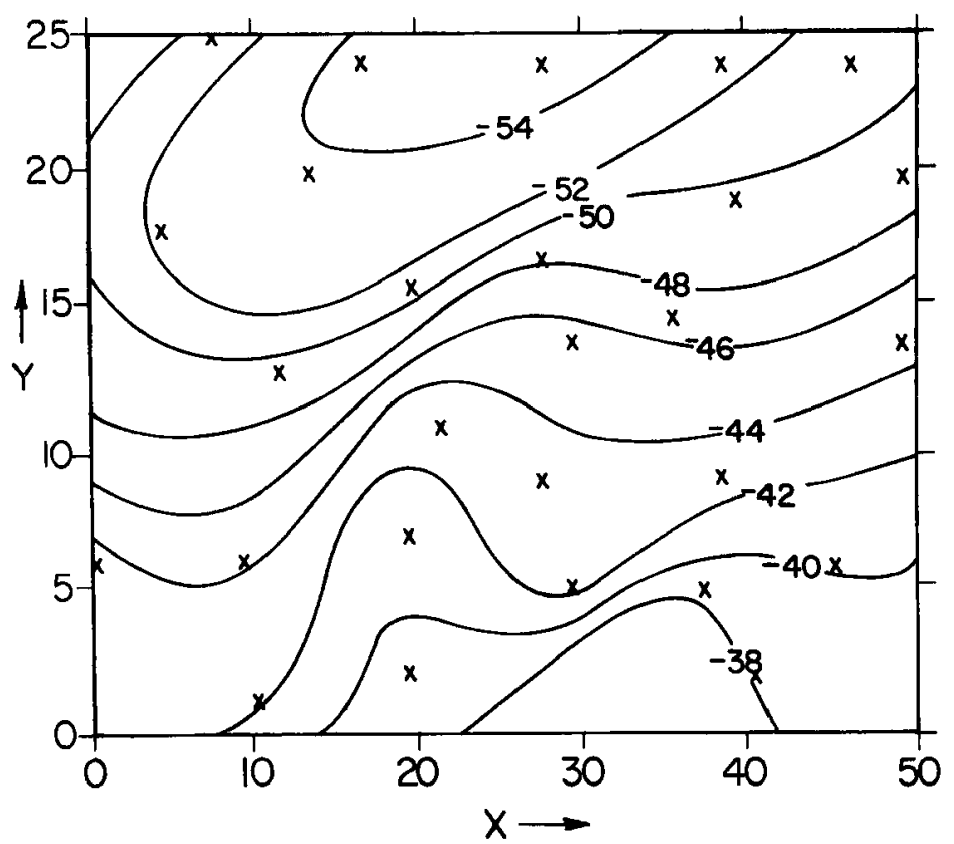

Fig. 14: Subjective analysis of the $300 \mathrm{mb}$ temperatures for central United States, 00 GMT, December 28, 1966. Radiosonde locations are indicated by $\mathrm{X}$. 


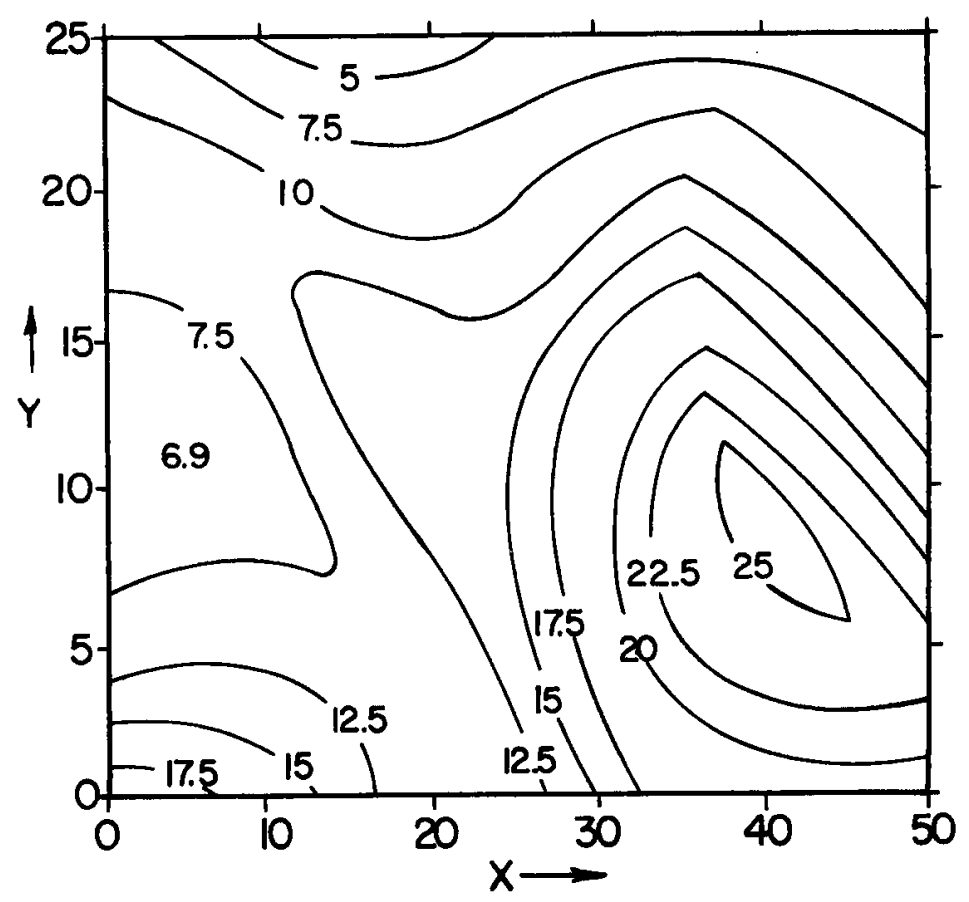

Fig. 15: Spline analysis of the $850 \mathrm{mb}$ winds for central United States, OO GMT, December 28, 1966.

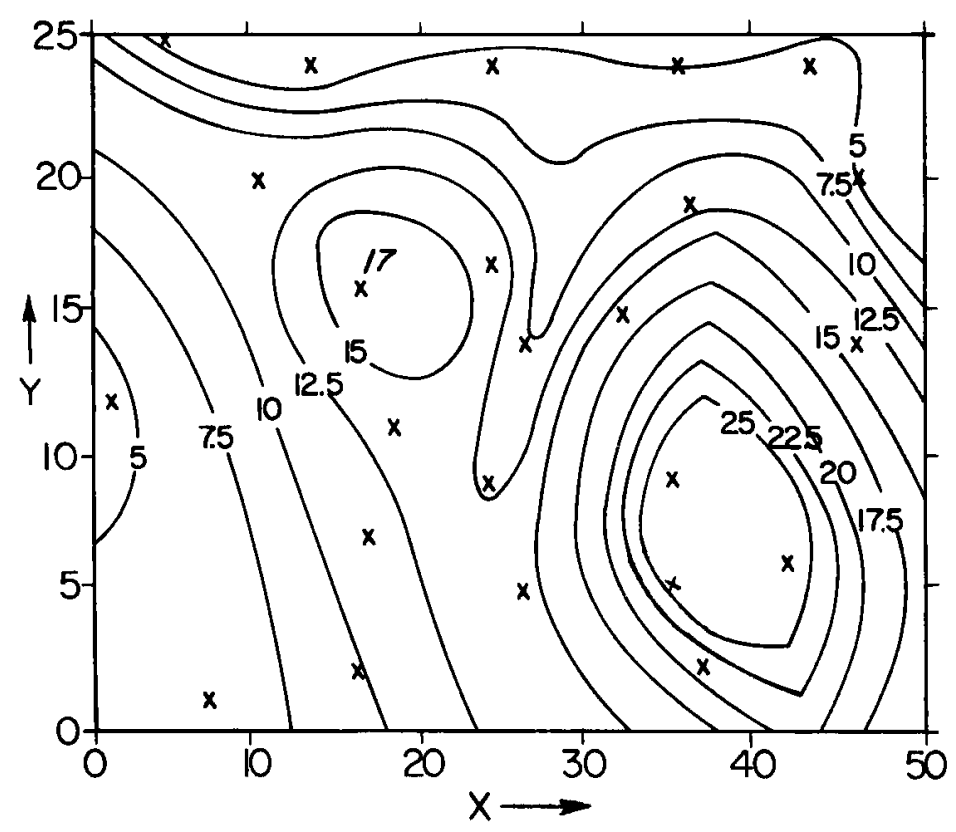

Fig. 16: Subjective analysis of the $850 \mathrm{mb}$ winds for central United States, $00 \mathrm{GMT}$, December 28, 1966. Radiosonde locations are indicated by $\mathrm{X}$. 


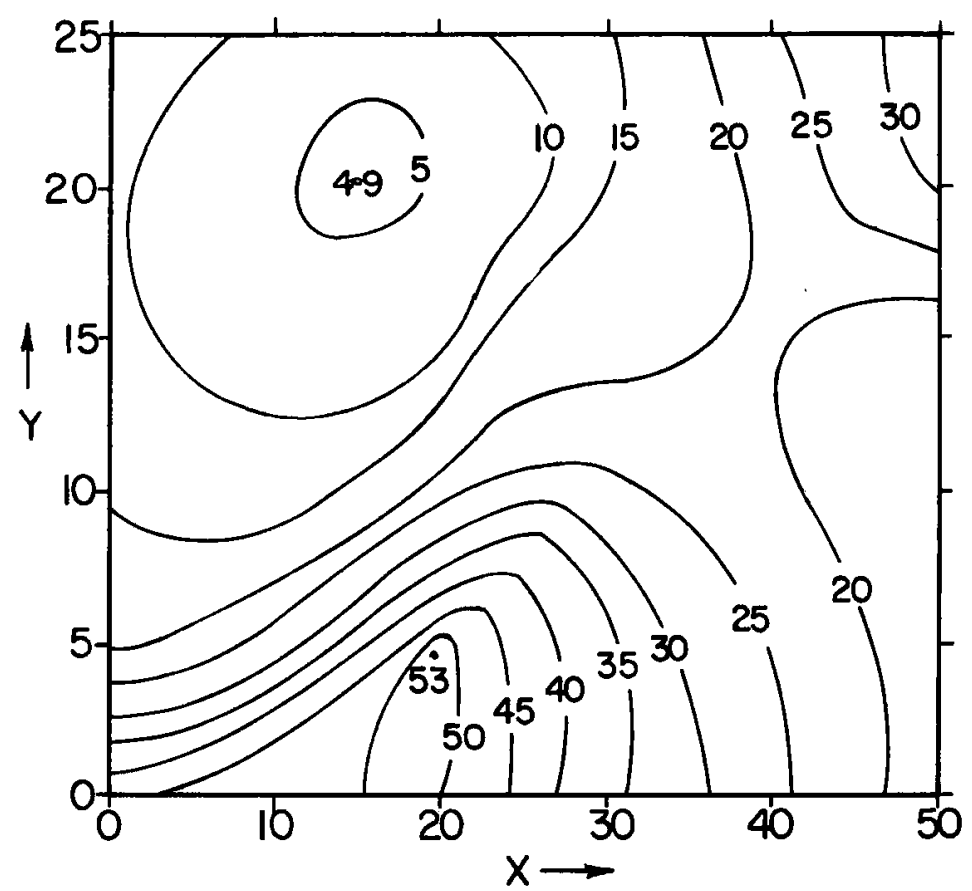

Fig. 17: Spline analysis of the $500 \mathrm{mb}$ winds. for central United States, 00 GMT, December 28, 1966.

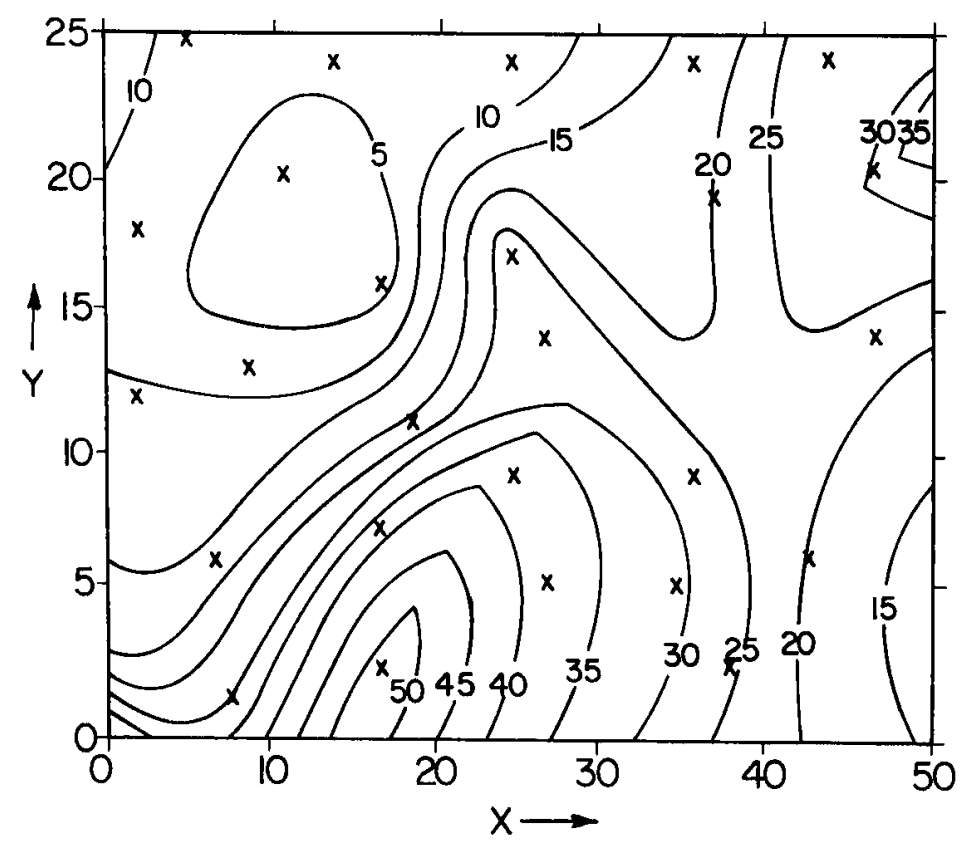

Fig. 18: Subjective analysis of the $500 \mathrm{mb}$ winds for central United States, 00 GMT, December 28, 1966. Radiosonde locations are indicated by $\mathrm{X}$. 


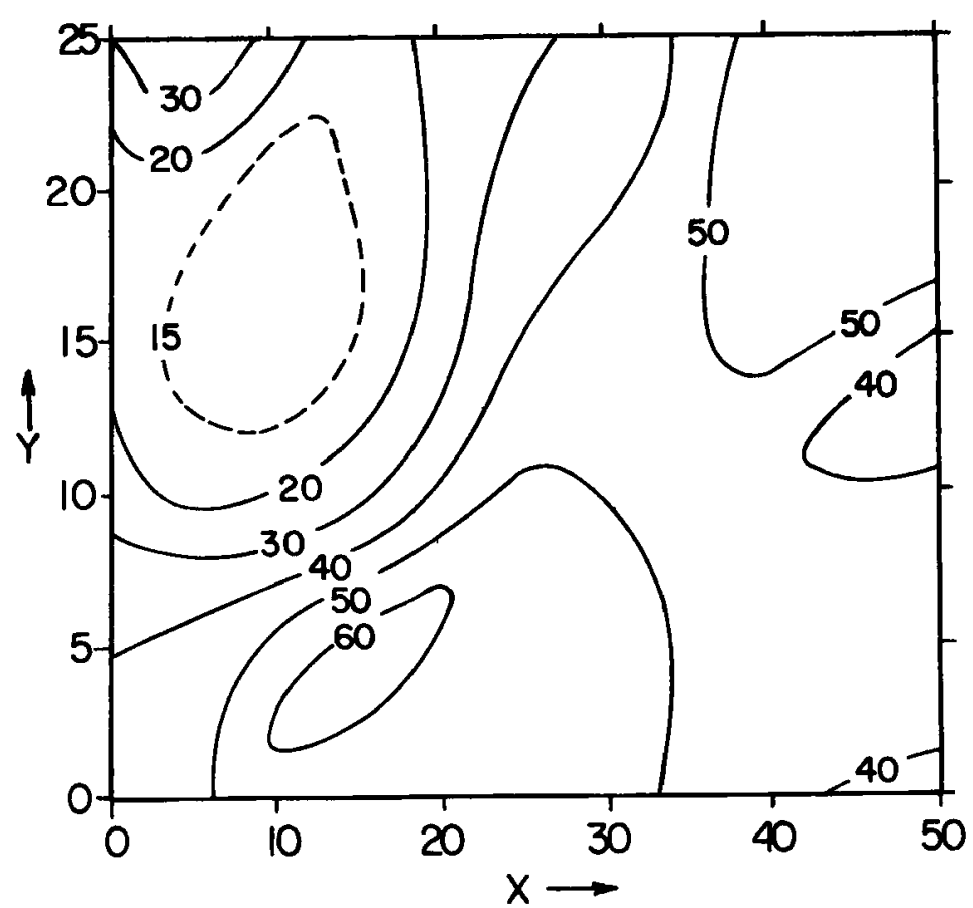

Fig. 19: Spline analysis. of the $300 \mathrm{mb}$ winds for central United States, 00 GMT, December 28, 1966.

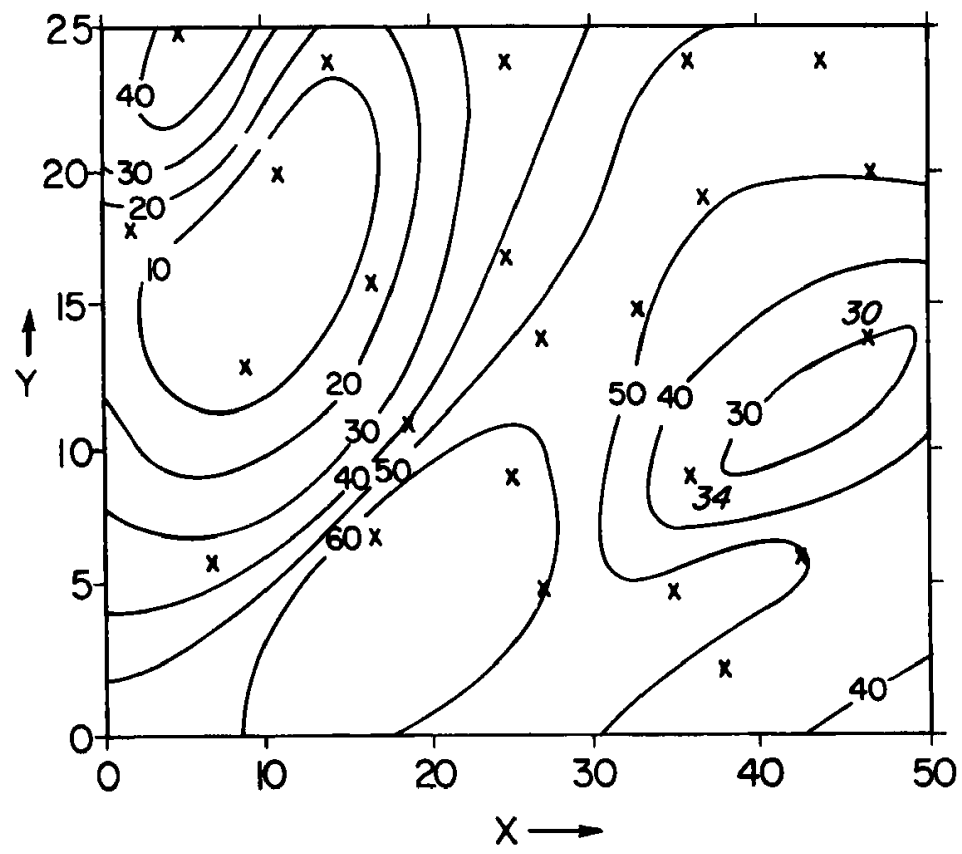

Fig. 20: Subjective analysis of the $300 \mathrm{mb}$ winds for central United States, 00 GMT, December 28, 1966. Radiosonde locations are indicated by $\mathrm{X}$. 


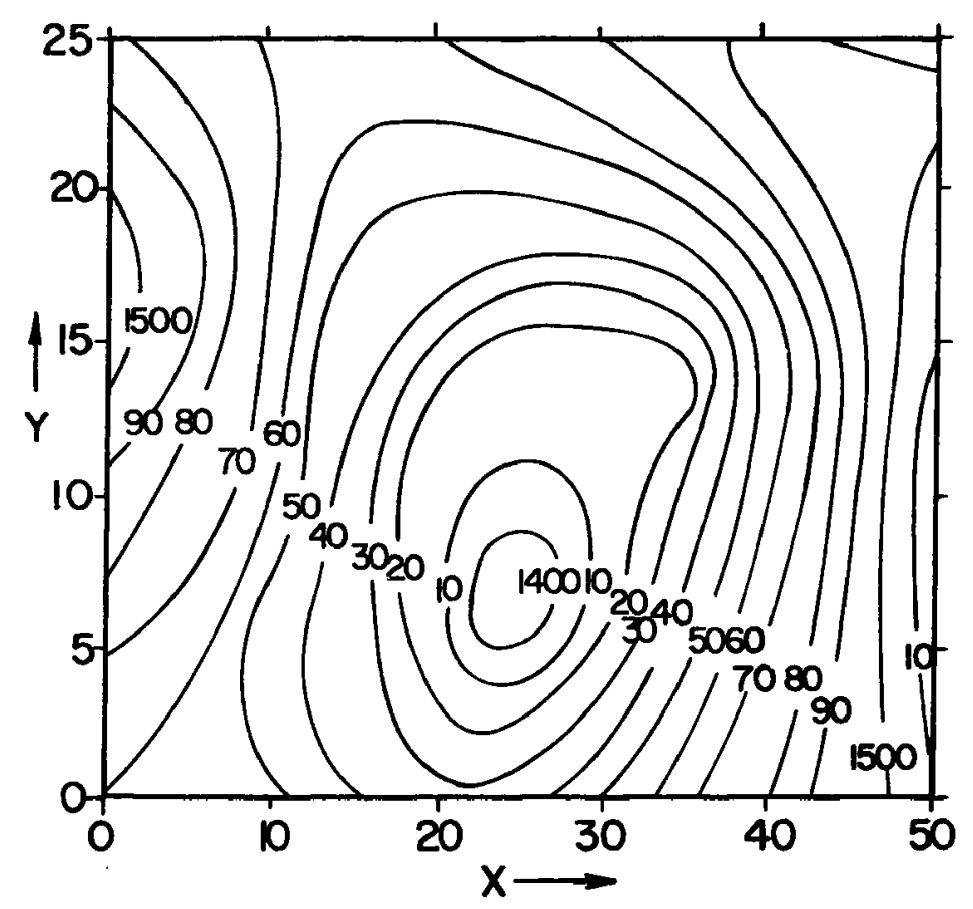

Fig. 21: Spline analysis of the $850 \mathrm{mb}$ geopotential heights for central United States, OO GMT, December 28, 1966.

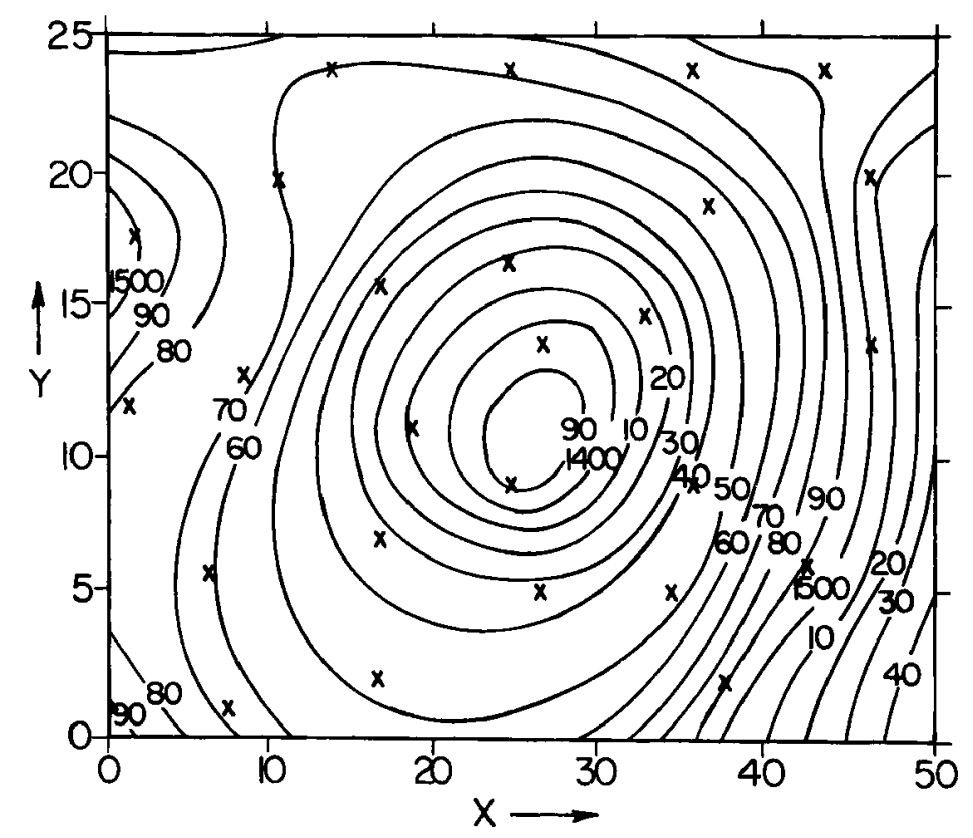

Fig. 22: Subjective analysis of the $850 \mathrm{mb}$ geopotential heights for central United States, 00 GMT, Decenber 28, 1966. Radiosonde locations are indicated by $\mathrm{X}$. 


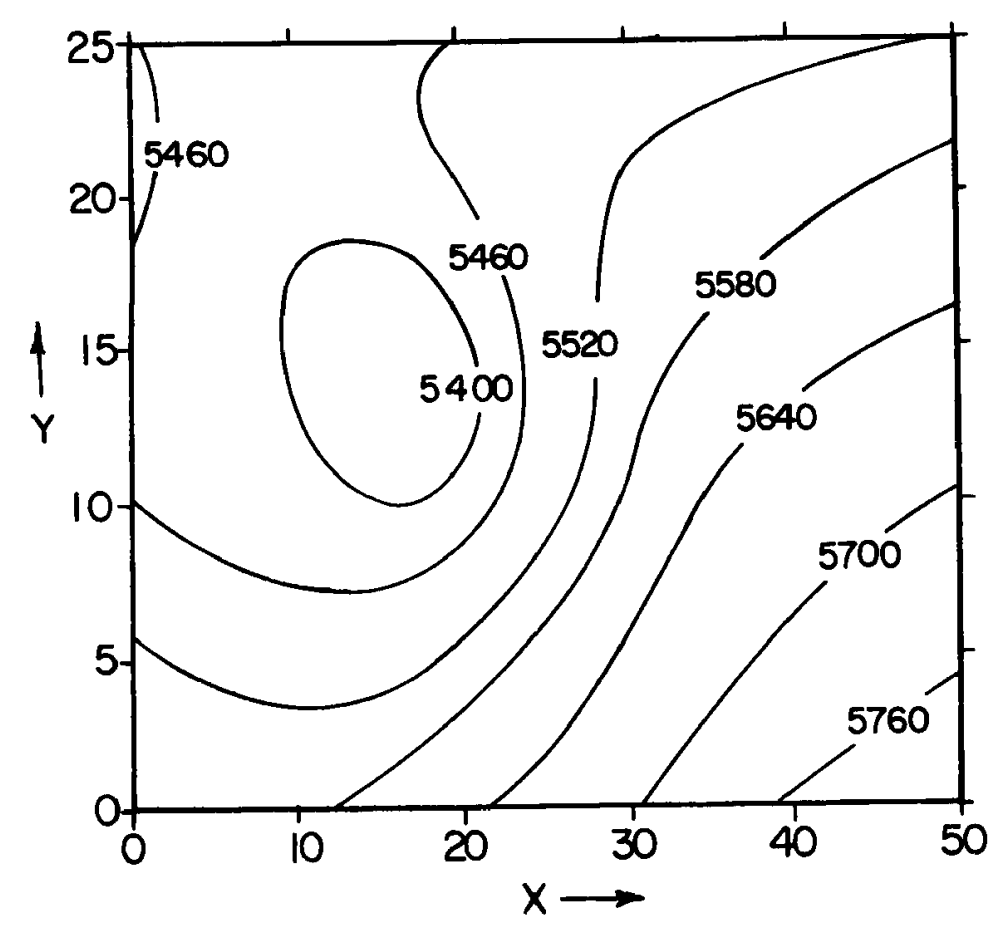

Fig. 23: Spline analysis of the $500 \mathrm{mb}$ geopotential heights for central United States, 00 GMT, December 28, 1966.

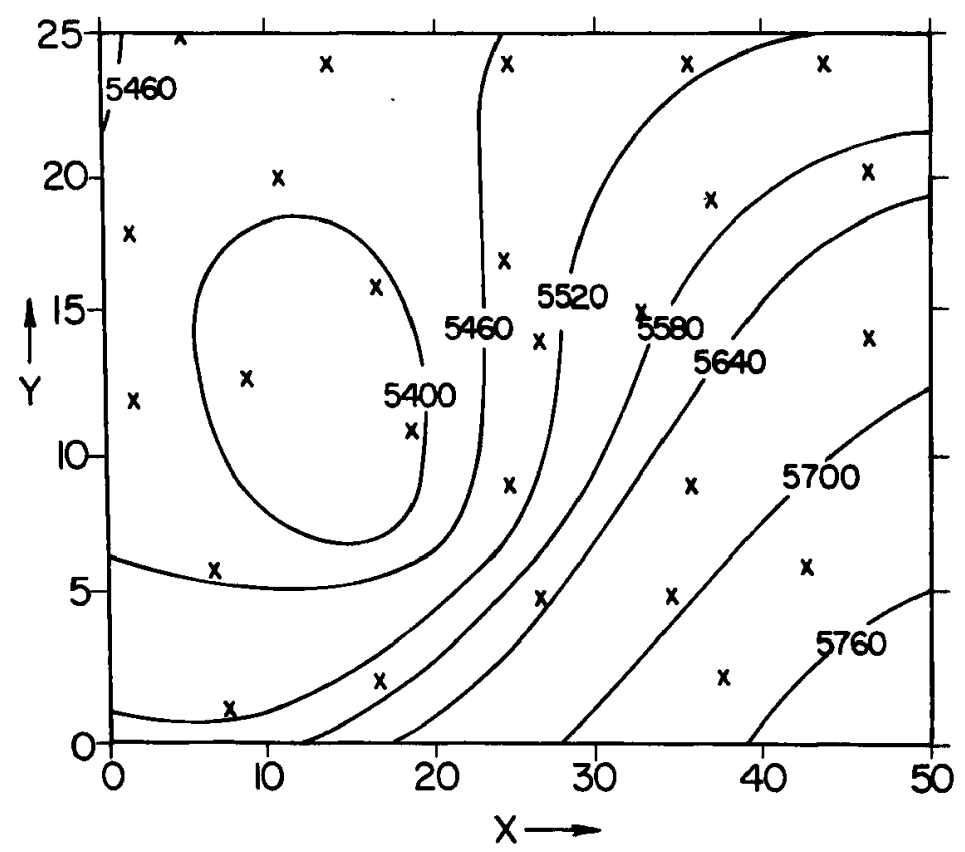

Fig. 24: Subjective analysis of the $500 \mathrm{mb}$ geopotential heights for central United States, OO GMT, December 28, 1966. Radiosonde locations are indicated by $\mathrm{X}$. 


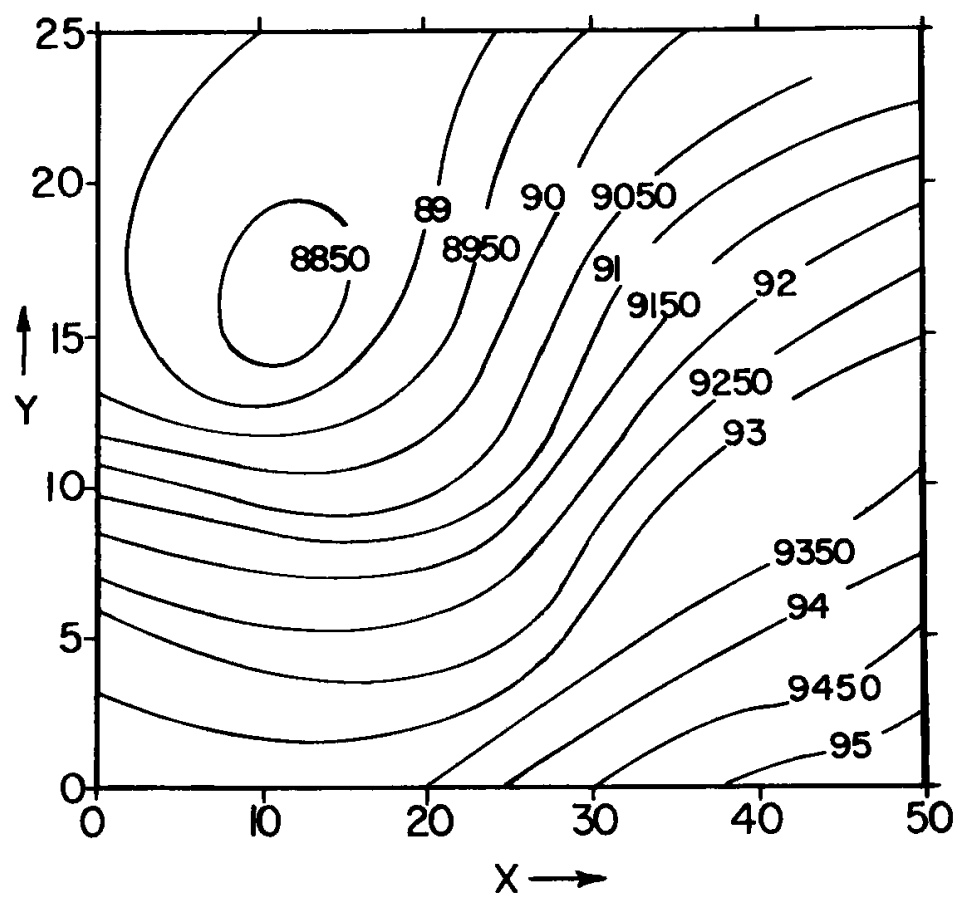

Fig. 25: Spline analysis of the $300 \mathrm{mb}$ geopotential heights for centra1 United States, 00 GMT, December 28, 1966.

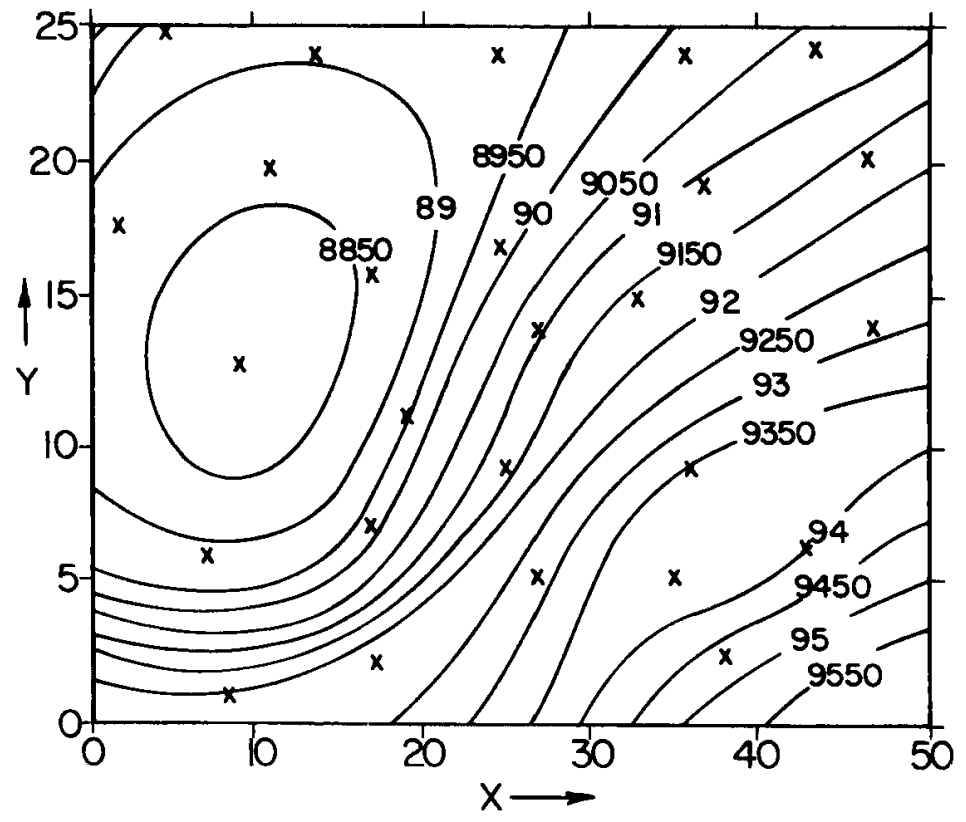

Fig. 26: Subjective analysis of the $300 \mathrm{mb}$ geopotential heights for central United States, 00 GMT, December 28, 1966. Radiosonde locations are indicated by $\mathrm{x}$. 


\section{Conclusions}

Objective analysis by the spline technique appears to be a satisfactory method for two dimensional data analysis. Analysis of regions with poor data coverage also appears to give satisfactory results except in those situations where the features being analyzed are defined by less than three pieces of data. The magnitude of the gradient of the data to be analyzed does not seem to have any undesirable effects on the performance of the technique, provided that the input parameters are properly defined. 
References

Ahlberg, J.H. and E.N. Nilson, 1963: Convergence properties of the spline fit. J. Soc. Indust. App1. Math., Vol. 11.

Aubert, E.J., 1959: Objective map analysis utilizing the concept of circulation and vorticity. Jour. of Meteor., Vol. 16, No. 4.

Berggren, R., 1957: On the accuracy of $500 \mathrm{mb}$ analysis with special reference to numerical forecasting. Tellus, Vol. 9 , No. 3 .

Bergthorsson, P. and B.R. Doos, 1955: Numerical weather-map analysis. Tellus, Vol. 7, No. 3 .

Best, W.H., 1956: Differences in numerical prognoses resulting from differences in analyses. Tellus, Vol. 8, No. 3.

Birkhoff, G., 1964: Symposium on Approximation of Functions. Warren, Michigan.

Cressman, G.P., 1959: An operational objective-analysis system. Mon. Wea. Rev., Vo1. 87, No. 10.

Curtis, A.R. and M.J.D. Powe11, 1966: Using cubic splines to approximate functions of one variable to prescribe accuracy. Report No. HL 66/6251 (T.P. 252), A.E.R.E., Harwe11.

Doos, B.R. and M.A. Eaton, 1957: Upper-air analysis over ocean areas. Tellus, Vol. 9, No. 2 .

Fowler, A.H. and C.W. Wilson, 1962: Cubic spline, a curve fitting routine. Report No. Y-1400, Oak Ridge National Laboratory.

Gandin, L.S., 1965: Objective analysis of meteorological fields. U.S. Dept. of Commerce, Clearing House for Federal Scientific and Technical Information, N66-18047.

Gilchrist, B. and G.P. Cressman, 1954: An experiment in objectibe analysis. Tellus, Vo1.6.

Holladay, J.C., 1957: Smoothest curve approximation. Math. Tables. Aids to Comp., Vol. 11 .

Johnson, D.H., 1957: Preliminary research in objective analysis. Tellus, Vol. 9 , No. 3 .

Kibel, I.A., 1945: An example of non-uniform turbulence in a compressible fluid. Doklady ANSSSR, Vol. 49, No. 4.

Love, A.E.H., 1934: The Mathematical Theory of Elasticity. Fourth edition, Cambridge Univ. Press.,London. 
Masuda, Y. and A. Arakawa, 1962: On the objective analysis for surface and upper level maps. Proceedings of the International Symposium on Numerical Weather Prediction in Tokyo, November 7-13, 1960. S. Syono, editor, pp. 55-66, Meteorological Society of Japan, $656 \mathrm{pp}$.

Panofsky, H.A., 1949: Objective weather map analysis. Jour. of Meteor., Vol. 6, No. 6 .

Pearce, R.P. and H. Rieh1, 1968: Studies on interaction between synoptic and mesoscale weather elements in the tropics. Atmos. Science Paper No. 126, Colorado State Univ., Fort Collins.

Sasaki, Y., 1958: An objective analysis based on the variational method. Jour. of Meteor. Soc. Japan, Vol. 36, No. 3 .

Teweles, S. and M. Snidero, 1962: Some problems of numerical objective analysis of stratospheric constant-pressure surfaces. Mon. Wea. Rev., Vol. 90 , No. 4 .

Walsh, J.L., J.H. Ahlberg and E.N. Nilson, 1962: Best approximation properties of the spline fit. J. Math. Mech., Vol. 11. 